LA W RENCE LIVERM ORE N A TIO NAL LABORATORY
Aerodynamic drag reduction of class 8 heavy vehicles: a full-scale wind tunnel study

J. Ortega, K. Salari, A. Brown, R. Schoon 
This document was prepared as an account of work sponsored by an agency of the United States government. Neither the United States government nor Lawrence Livermore National Security, LLC, nor any of their employees makes any warranty, expressed or implied, or assumes any legal liability or responsibility for the accuracy, completeness, or usefulness of any information, apparatus, product, or process disclosed, or represents that its use would not infringe privately owned rights. Reference herein to any specific commercial product, process, or service by trade name, trademark, manufacturer, or otherwise does not necessarily constitute or imply its endorsement, recommendation, or favoring by the United States government or Lawrence Livermore National Security, LLC. The views and opinions of authors expressed herein do not necessarily state or reflect those of the United States government or Lawrence Livermore National Security, LLC, and shall not be used for advertising or product endorsement purposes.

This work performed under the auspices of the U.S. Department of Energy by Lawrence Livermore National Laboratory under Contract DE-AC52-07NA27344. 


\title{
Aerodynamic drag reduction of class 8 heavy vehicles: a full-scale wind tunnel study
}

\author{
J. Ortega $\stackrel{*}{*}$ K. Salari $\ddagger$ A. Brown $\stackrel{\ddagger}{\ddagger}$ R. Schoon ${ }^{\S}$
}

$11 / 28 / 2012$

Corresponding author: Kambiz Salari, Lawrence Livermore National Laboratory, P.O. Box 808, L-090, Livermore, CA 94551; e-mail: salari1@llnl.gov; phone: 925-424-4635

\footnotetext{
*Staff Scientist, Engineering, Lawrence Livermore National Laboratory, Livermore, CA †Staff Scientist, Computation, Lawrence Livermore National Laboratory, Livermore, CA

${ }^{\ddagger}$ Former Aerodynamics Experimental Engineer, Navistar, Inc., Fort Wayne, IN

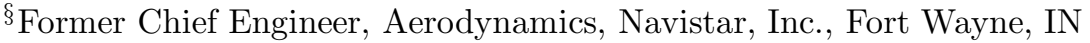




\section{Abstract}

A wind tunnel investigation is conducted to evaluate the performance of both commerciallyavailable and prototype aerodynamic drag reduction devices for modern class 8 heavy vehicles. Drag force measurements are made on three full-scale, heavy vehicle configurations at a Reynolds number of $4.6 \times 10^{6}$ based upon the vehicle width. The wind-averaged drag coefficient is calculated from the wind tunnel measurements and used to estimate the fuel savings afforded by individual and combinations of devices. For the tractor-trailer gap, the most effective modification is found to be reducing the gap size. Numerous trailer skirts are installed on the three heavy vehicle configurations and the resulting change in the windaveraged drag coefficient is shown to have a nominally linear dependence upon the change in the trailer skirt area. The trailer base drag is alleviated through the installation of boattail devices. When used in combination, the devices often provide a reduction in drag that is greater than the individual contribution from each device. For the best vehicle configurations, the wind-averaged drag coefficient and the resulting estimated fuel use decrease by 0.097 to 0.150 and approximately 10000 to $15000 \mathrm{~L}$ per $2.012 \times 10^{8} \mathrm{~m}$ of highway mileage driven, respectively.

Keywords: class 8 heavy vehicle, aerodynamic drag reduction device, wind-averaged drag coefficient 


\section{Introduction}

Combination heavy vehicles in the United States consume approximately 30 billion gallons of fuel each year [17]. By 2035, this number is expected to increase to approximately 40 billion gallons per year as a result of the continued growth of the highway transportation sector [1]. The majority of the shaft power derived from this fuel is used to overcome aerodynamic drag at highway speeds, while the remaining portion is dissipated through tire rolling resistance and drive train friction [5, 46].

These aerodynamic losses were first given considerable attention following the 1970's oil crisis. Prior to that time, heavy vehicles were primarily designed for functionality and ease of manufacturing and, therefore, little thought was given to aerodynamics, which resulted in box-shaped tractors and trailers. To improve the fuel economy of these vehicles, several conference workshops and numerous research programs and studies were conducted on heavy vehicle aerodynamics $[5,6,8,9,10,11,12,16,21,28,29,33,36,37,38,39,47,48,50$, $53,56,57,58,64]$. Although the entire vehicle was investigated for various avenues of reducing drag, the primary focus of these efforts was the aerodynamics of the tractor and the front of the trailer. From wind tunnel, track, and road test data, it was shown that considerable reductions in aerodynamic drag could be achieved through tractor roof fairings, skirts, aerodynamic visors, rounding of the tractor and trailer front edges, and through the installation of trailer nose cones. Since these modifications did not significantly hamper the operational performance of the heavy vehicles, the trucking industry generally accepted them, which led to a definitive transition to the modern aerodynamic tractor and the rounded, front-corner trailer. These aerodynamic changes, along with improvements in tire, engine, and component designs, resulted in an increase in the fuel economy of heavy vehicles from $99000 \mathrm{~L} / 2.012 \times 10^{8} \mathrm{~m}$ driven $(4.8 \mathrm{mpg})$ in 1970 to $88000 \mathrm{~L} / 2.012 \times 10^{8} \mathrm{~m}$ driven $(5.4 \mathrm{mpg})$ in 2008 , where $2.012 \times 10^{8} \mathrm{~m}(125000 \mathrm{mi})$ is a nominal distance traveled by a heavy vehicle each year [17]. For more thorough reviews of the early aerodynamic developments of heavy 
vehicles, the reader is directed to $[13,14,38,48,49]$.

With the present day rise of fuel costs and the uncertainty of foreign oil supplies, there is a continued demand in the United States for increased fuel economy of heavy vehicles. Therefore, a number of the drag reduction devices and concepts that were not originally implemented in the design of modern day heavy vehicles have become potential candidates for further fuel economy improvements. Some of these second generation devices include boattails and trailer skirts, as well as tractor-trailer gap devices $[2,3,7,9,12,13,14,15,22$, $23,31,32,35,38,42,44,45,54,55,59,60,61,62]$. A number of studies, a sampling of which are shown in Tables 1-4, have either measured or estimated that these devices can produce fuel economy improvements when they are used both individually and in combination with one another. (It should be noted that the fuel savings data summarized in each of these tables are for various tractor-trailer geometries, Reynolds numbers, and drag reduction device designs.) From these studies, the average fuel savings of the gap, skirt, and boattail devices are about 3000, 5000, and $4000 \mathrm{~L} / 2.012 \times 10^{8} \mathrm{~m}$ driven of highway mileage, respectively, while that of their combinations is on average approximately $12000 \mathrm{~L} / 2.012 \times 10^{8} \mathrm{~m}$ driven of highway mileage. Other research concepts that have been recently investigated include tractor and trailer base blowing systems [18, 19, 43], fluidic actuators $[26,41,51,52,63]$ and trailer wheel and bogie fairings [15, 42, 55].

Despite the fuel economy benefits of these second generation devices, they have not been widely accepted by the trucking industry due to both operational issues and the nature of heavy vehicle manufacturing in the United States. Unlike the first generation devices, a number of the second generation devices are more susceptible to damage, restrict access to portions of the vehicle, or must be continually deployed and stowed during routine operations. For example, the trailer skirts reduce the ground clearance of the vehicle, causing them to scrape against the ground at railroad crossings and sunken loading docks. In addition, the skirts can limit access to the trailer underbody for tire and brake inspections. The 
gap devices, especially those constructed from aluminum sheet metal, are prone to damage during maneuvers that require the vehicle to articulate to extreme angles. Boattails are the least accepted of these devices since the trailer base upon which they are installed receives the most interaction during fleet operations. As a result, the boattail must be stowed before backing the trailer into the loading dock, thus requiring the driver or dock worker to manually perform this additional task. Some manufacturers attempt to circumvent this step by designing the boattail to self-retract when the vehicle comes to a stop. However, freezing and snowy conditions can potentially hamper this self-actuation motion. As a result of these many shortcomings, the majority of fleet operators have purposely decided not to adopt these devices in their current forms [30].

Clearly, there is a need to improve the design of second generation devices so that the trucking industry will welcome them and thereby benefit from the fuel economy gains that can be had through their implementation. This can only be accomplished through a coordinated effort of the trucking industry, aerodynamic researchers, and government regulations [13]. Therefore, we have formed a multi-disciplinary team comprised of trucking industry manufacturers (tractor, trailer, tire, and drag reduction devices), a commercial fleet, and a national laboratory. The ultimate goal of this team is to develop a trailer with factoryinstalled devices that are not only effective in reducing aerodynamic drag, but are also robust and operationally-minded.

The purpose of the present study is to take the first step towards accomplishing this goal by evaluating the performance of a number of drag reduction devices, the majority of which are currently on the market. A full-scale wind tunnel investigation is employed to measure the changes in the drag coefficient that arise from the installation of these devices and to obtain a better understanding of how different devices affect the performance of other devices installed simultaneously. The utility of this experimental approach is that it provides a controlled environment for investigating the devices under varying wind speeds and vehicle 
yaw angles, as well as eliminating any Reynolds number effects. In addition, the full-scale model obviously has all of the details of a modern heavy vehicle along with those specific to the various drag reduction devices. Similar full-scale wind tunnel studies of heavy vehicles and devices have been conducted in the past, though these were restricted to either a limited number of devices or to a shortened trailer with a high tunnel blockage due to size restrictions of the wind tunnel test section $[15,31,32]$. Before discussing the wind tunnel setup, we first describe in the following section the theory of the wind-averaged drag coefficient, which is employed as a metric for comparing the performance of the various devices.

\section{Wind-Averaged Drag Coefficient}

When a vehicle is in motion, the body-axis drag coefficient is given by the expression, $C_{A}=D_{A} /\left(\frac{1}{2} \rho V_{r}^{2} A\right)$, where $D_{A}$ is the drag force in the direction along the axis of the vehicle, $V_{r}$ is the wind speed relative the vehicle, $\rho$ is the air density, and $A$ is the vehicle crosssectional area. While the information obtained from $C_{A}$ at multiple yaw angles, $\psi$, is useful, it is somewhat cumbersome since this quantity does not summarize the performance of a drag reduction device into a single quantity that can be easily compared to that of other devices. In addition, the mean value of $C_{A}$ over a range of yaw angles is insufficient since it does not account for the fact that crosswind velocities cause a vehicle traveling at a particular speed to experience certain yaw angles more than others. A quantity that resolves both of these issues is the wind-averaged drag coefficient, $C_{A_{\text {wavg }}}$, which is derived as follows $[5,8,27]$.

Assume that a vehicle is traveling at a velocity $V_{t}$ with respect to the roadway and there is a crosswind that has a velocity $V_{w}$ at the mid-height of the vehicle acting at an angle $\phi$ with respect to $V_{t}$ (Fig. 1). The total speed of the wind relative to the vehicle is given by

$$
V_{r}=V_{t} \sqrt{1+2\left(V_{w} / V_{t}\right) \cos \phi+\left(V_{w} / V_{t}\right)^{2}}
$$


and the yaw angle by

$$
\tan (\psi)=\frac{\left(V_{w} / V_{t}\right) \sin \phi}{1+\left(V_{w} / V_{t}\right) \cos \phi}
$$

The wind-averaged drag force is found from

$$
\begin{gathered}
D_{A_{\text {wav }}}=\int_{0}^{2 \pi} \int_{0}^{V_{w_{\max }}} D_{A} p\left(V_{w}, \phi\right) d V_{w} d \phi \\
D_{A_{\text {wav }}}=\int_{0}^{2 \pi} \int_{0}^{V_{w_{\max }}} C_{A}(\psi) \frac{1}{2} \rho V_{r}^{2} A p\left(V_{w}, \phi\right) d V_{w} d \phi \\
D_{A_{\text {wavg }}}=\int_{0}^{2 \pi} \int_{0}^{V_{w_{\text {max }}}} C_{A}(\psi) \frac{1}{2} \rho V_{t}^{2}\left(1+2\left(V_{w} / V_{t}\right) \cos \phi+\left(V_{w} / V_{t}\right)^{2}\right) A p\left(V_{w}, \phi\right) d V_{w} d \phi
\end{gathered}
$$

where $p\left(V_{w}, \phi\right)$ is the probability of a wind speed $V_{w}$ blowing at an angle $\phi$ with respect to the vehicle and $V_{w_{\max }}$ is the maximum wind speed. Dividing Eq. 5 by $\frac{1}{2} \rho V_{t}^{2} A$ gives the wind-averaged drag coefficient. Assuming that the wind speed, $V_{w}$, is determined from a national average and that it has an equal probability of occurring in any direction, such that $p\left(V_{w}, \phi\right)=1 / 2 \pi$, and that the vehicle is symmetric about its longitudinal body axis, gives a wind-averaged drag coefficient of

$$
C_{A_{\text {wavg }}}=\frac{1}{\pi} \int_{0}^{\pi} C_{A}(\psi)\left(1+2\left(V_{w} / V_{t}\right) \cos \phi+\left(V_{w} / V_{t}\right)^{2}\right) d \phi
$$

Equation 6 can be numerically integrated from

$$
C_{A_{\text {wavg }}}=\frac{1}{6} \sum_{j=1}^{6} M(j) C_{A}(\psi(j))
$$

where

$$
M(j)=1+2\left(V_{w} / V_{t}\right) \cos \phi(j)+\left(V_{w} / V_{t}\right)^{2}
$$




$$
\begin{gathered}
\phi(j)=\frac{\pi}{6} j-\frac{\pi}{12} \\
\psi(j)=\tan ^{-1} \frac{\left(V_{w} / V_{t}\right) \sin \phi(j)}{1+\left(V_{w} / V_{t}\right) \cos \phi(j)}
\end{gathered}
$$

The power needed to overcome this aerodynamic drag force is given by

$$
P=\frac{D_{A_{w a v g}} V_{t}}{\eta}=\frac{\frac{1}{2} \rho V_{t}^{2} A C_{A_{w a v g}} V_{t}}{\eta}
$$

where $\eta$ is the driveline efficiency of the heavy vehicle. The amount of fuel, $\mu$, used by the engine to produce this power can be estimated from

$$
\begin{gathered}
\mu=\frac{\gamma}{V_{t}} P=\frac{\gamma}{V_{t}} \frac{\frac{1}{2} \rho V_{t}^{2} A C_{A_{w a v g}} V_{t}}{\eta} \\
\mu=\frac{\gamma}{\eta} \frac{1}{2} \rho V_{t}^{2} A C_{A_{\text {wavg }}}
\end{gathered}
$$

where $\gamma$ is the specific fuel consumption rate of the engine. The change in fuel usage due to the installation of a drag reduction device is thus given by

$$
\Delta \mu=\frac{\gamma}{\eta} \frac{1}{2} \rho V_{t}^{2} A \Delta C_{A_{\text {wavg }}}
$$

where $\Delta C_{A_{\text {wav }}}$ is the corresponding reduction in the wind-averaged drag coefficient.

\section{$3 \quad$ Wind Tunnel Setup}

The body-axis drag coefficient data is acquired by making drag force measurements on three full-scale tractor-trailer vehicles: a 2008 Navistar ProStar long sleeper (LS) tractor 
with a Wabash 16.2 m straight-frame (SF), dry freight trailer; a 2008 Navistar ProStar daycab (DC) tractor with the SF trailer; and the DC tractor with a Kentucky Trailer $16.2 \mathrm{~m}$ drop-frame (DF), dry freight trailer (Fig. 2a-c). These vehicles have overall lengths ranging from 20 to $22 \mathrm{~m}$ and cross-sectional areas of $10.5 \mathrm{~m}^{2}, 10.5 \mathrm{~m}^{2}$, and $10.6 \mathrm{~m}^{2}$, respectively. The gap between the tractor and trailer is set to $1.1 \mathrm{~m}$ for each baseline vehicle configuration and the trailer bogie on the SF trailer is positioned such that the midpoint between the trailer wheels is $3.7 \mathrm{~m}$ from the trailer base. The measurements are made within the NASA Ames $80 \times 120$ wind tunnel, which has a contraction ratio of 5:1 and a test section cross-section of $24.4 \mathrm{~m} \times 36.6 \mathrm{~m}$. Aside from a few select runs at speeds as low as $8.9 \mathrm{~m} / \mathrm{s}(20 \mathrm{mph})$ and as high as $35.8 \mathrm{~m} / \mathrm{s}(80 \mathrm{mph})$, the nominal tunnel speed is set to $U_{\circ}=25.9 \mathrm{~m} / \mathrm{s}(58$ mph, dynamic pressure of $420 \mathrm{~Pa}$ ) with a free-stream turbulence intensity of $\approx 1 \%$ [67]. The resulting Reynolds number, $R e_{w}=U_{o} w / \nu$, based upon the trailer width, $w=2.6 \mathrm{~m}$, is $4.6 \times 10^{6}$, where $\nu$ is the kinematic viscosity of air. Although this tunnel speed is slightly less than the typical highway speed in the United States $(29.1 \mathrm{~m} / \mathrm{s}$ or $65 \mathrm{mph})$, a series of runs at various tunnel speeds shows that the wind-averaged drag coefficient is relatively independent of Reynolds number by $R e_{w}=4.6 \times 10^{6}$ (Fig. $2 \mathrm{~d}$ ). The front of each tractor is positioned approximately one vehicle length downstream of the test section inlet. From the measurements of Zell [67], the boundary layer displacement thickness is on the order of $10^{-1}$ m approximately $1 \mathrm{~m}$ and $3.0 \mathrm{~m}$ upstream of the LS and DC tractors, respectively, within the empty tunnel. When the vehicles are yawed about the $z$-axis to the maximum extent of $15^{\circ}$ relative to the free-stream velocity, the blockage within the test section is only $\approx 3 \%$ and, therefore, no blockage corrections are applied to the drag measurements.

The heavy vehicle is supported by a system similar to that of Cooper \& Leuschen [15] and Leuschen \& Cooper [32], which permits the vehicle to partially rest upon the tunnel and turntable floor, while still transmitting the drag force to the balance (Fig. 2c). This is accomplished by placing aluminum plates beneath the tractor steering wheels and trailer 
wheels and resting these wheels upon air bearings, which receive a continuous air supply from the wind tunnel facility. When the air bearings are inflated, the bottom of the tires is about $0.15 \mathrm{~m}$ above the tunnel floor, placing them at the approximate height of the boundary layer displacement thickness at the front of the vehicle. The tractor drive wheels are chocked and strapped to a steel plate that is fixed to the balance. The low friction coefficient provided by the air bearings thus makes it possible to transmit not only the drag force, but also the side force and the yawing moment to the balance through the tractor drive wheels. Since the steering wheels of the LS tractor extend beyond the edge of the turntable onto the tunnel floor, the aluminum plate beneath these wheels must be large enough to allow the air bearings to remain on the plate as the vehicle is yawed. For the shorter DC tractor, the steering wheels remain on turntable and, as a result, much smaller aluminum plates are employed beneath these wheels. The same approach is used for the trailer wheels that are located on the turntable. Although the tractor and trailer remain rigid relative to one another through the use of turnbuckles and chains, flexure of the entire vehicle does occur relative to the steel plate supporting the tractor wheels as a result of the compliant the tractor tires. Depending on the location of the center of pressure on the vehicle, rotation about the steel plate can alter the vehicle yaw angle by as much as $1^{\circ}$. To account for this non-negligible amount of rotation, a photo-electric proximity sensor (SICK DT 10-P10B5 accurate to $\pm 0.006 \mathrm{~m}$ ) and optical target are placed on the aluminum trailer wheel plate and trailer wheel air bearing, respectively. Using the proximity sensor and turntable yaw angle data, the actual yaw angle of the vehicle is then calculated.

The external balance system used to measure the drag force has a range of $\pm 2.224 \times 10^{5}$ $\mathrm{N}$ with an accuracy of $\pm 53 \mathrm{~N}$ over this entire range. However, only a small fraction $(\approx 2 \%)$ of this range is utilized for the vehicle drag. To determine the balance accuracy over this much smaller range, check loads are applied to the installed vehicle by hanging known weights on a pulley system with a load cell (Dillon ED Xtreme, $11120 \mathrm{~N}$ capacity) accurate to within \pm 2.2 
$\mathrm{N}$. The resulting drag force measurement accuracy is found to be $\pm 44 \mathrm{~N}$, which is the same as that of a previous heavy vehicle study using this same balance [31]. Thus for the present study, we take the drag force accuracy of the balance to be $\pm 44 \mathrm{~N}$. Due to the fact that the vehicles span both the metric and non-metric portions of the balance system through the air bearings, it is also necessary to assess the drag force measurement error incurred by this aspect of the setup. This is accomplished by recording the drag force on the vehicle when it is rotated through a yaw sweep during a wind-off condition. For a perfectly rigid vehicle, balance system, air bearings, and tunnel floor and for completely frictionless air bearings, the resulting drag force should equal zero for all yaw angles. However, the results of this exercise demonstrate drag force errors of $\pm 58 \mathrm{~N}, \pm 19 \mathrm{~N}$, and $\pm 23 \mathrm{~N}$ for the LS/SF, DC/SF, and DC/DF configurations, respectively. Note that the LS/SF configuration has the largest error as a result of the steering wheel air bearings having to sweep across the surface of the aluminum plate, while those of the $\mathrm{DC} / \mathrm{SF}$ and $\mathrm{DC} / \mathrm{DF}$ configurations remain stationary relative to the smaller aluminum plates beneath the steering wheels.

During each experimental run, the vehicle is yawed on the turntable through a range of angles to simulate varying cross-winds from which the wind-averaged drag coefficient can be calculated. For the majority of the runs, the yaw sweep ranges from $-9^{\circ}$ to $+9^{\circ}$ in $3^{\circ}$ increments with an accuracy of $\pm 0.1^{\circ}$, though for a select number of runs, data is acquired from $-15^{\circ}$ to $+15^{\circ}$ in $3^{\circ}$ increments. Once the vehicle is at a desired yaw angle, the balance shaker and a shaker (Vibco Inc., SCR-1000) installed on the tractor chassis are activated for several seconds in order to settle both the balance and the air bearings beneath the vehicle wheels. Three data points per yaw angle are collected at $1024 \mathrm{~Hz}$ for 10 seconds per data point, which corresponds to about 12 to 13 vehicle length flow passes per data point for $U_{o}$ $=25.9 \mathrm{~m} / \mathrm{s}$. The wind-averaged drag coefficient is obtained by first averaging the measured $C_{A}(\psi)$ data at each value of $\pm \psi$ and then linearly interpolating this data to $\psi(\phi(j))$. The values of $C_{A_{\text {wavg }}}$ are calculated using $V_{t}=29.1 \mathrm{~m} / \mathrm{s}(65 \mathrm{mph})$ and $V_{w}=3.1 \mathrm{~m} / \mathrm{s}(7 \mathrm{mph})$, 
where $3.1 \mathrm{~m} / \mathrm{s}$ is the national-average wind speed in the United States at $2.1 \mathrm{~m}$ above the ground [5], and the resulting savings in the estimated fuel usage (Eq. 14) using $\rho=1.23$ $\mathrm{kg} / \mathrm{m}^{3}, \eta=0.85$, and $\gamma=7.639 \times 10^{-8} \mathrm{~L} / \mathrm{W} \cdot \mathrm{s}[5,8,9,32]$. Performing an uncertainty analysis [20] that takes into account the accuracy of the measurement systems, the drag force errors due to the air bearing setup, and the repeatability of the force measurements shows that the resulting errors in $C_{A_{\text {wavg }}}$ are $\pm 0.006, \pm 0.005$, and \pm 0.004 for the LS/SF, $\mathrm{DC} / \mathrm{SF}$, and DC/DF configurations, respectively. The 10 second sample time is shown to be adequate since increasing it to 20 seconds produces a change in the computed windaveraged drag coefficient that is smaller than the measurement error. In addition, the effects of flow hysteresis are shown to be negligible on $C_{A_{\text {wavg }}}$ when the direction of the yaw sweep is reversed. Since the steel plate and supporting hardware immediately beneath the tractor drive wheels protrude approximately $0.1 \mathrm{~m}$ into the boundary layer flow above the tunnel floor, they contribute an additional drag force to the balance system during a wind-on condition, resulting in a larger value of $C_{A_{\text {wavg }}}$. Measurements made without a vehicle installed on the balance reveal that this force is on the order of $160 \mathrm{~N}$. Due to the non-linear interactions of the boundary layer flow between the vehicle underside and the steel plate and supporting hardware, this force is not necessarily the same when the vehicle is installed on the balance and therefore it cannot simply be subtracted from the measured drag force. It is assumed that this force does not change significantly as drag reduction devices are installed since the devices typically reside rather far from the steel plate and supporting hardware. Therefore, no attempt is made to correct for this additional force in the present study.

Using this experimental procedure, the drag reduction characteristics are evaluated for devices that are installed in the tractor-trailer gap, trailer underbody, and trailer base. The three gap fairings (GP1, GP2, GP3), which attach to the front of the trailer, are comprised of curved plastic or aluminum plates that increase the radii of curvature of the front edge of the trailer sides and top (Figs. 2c, 3a-c). Other modifications to the tractor-trailer gap 
include reducing the distance between the back of the tractor to the front of the trailer from $1.1 \mathrm{~m}$ to $0.61 \mathrm{~m}$ (0.61m_gap), installing revised side extenders (REV_SE) that flare slightly outboard in order to accommodate the smaller tractor-trailer gap on the LS tractor, and filling the gap between the DC side extenders and the trailer front with aluminum sheets (FULL_SE)(Fig. 3d). The devices installed on the trailer underbody are various trailer skirts (SK\#), a prototype fairing (UBF1), and trailer wheel fairings (TWF1), the last of which are qualitatively similar to those in [5] (Figs. 4-5). For one trailer skirt design (SK5), adjustments are made to both the trailer skirt area and the angle of the skirt relative to the trailer side (Fig. 4e-g). Lastly, four boattails are installed on the trailer bases of various vehicle configurations (Fig. 6). While the boattails BT1 and BT2 have fixed angles, $\theta$, relative to the trailer, boattails BT3 and BT4 are designed to have variable deflection angles on the top and side boattail plates in order to determine an optimum angle setting. Since the plates used in the construction of these boattails are not perfectly flat, the measurement of the deflection angle is accurate to within only $\pm 2^{\circ}$.

\section{Results}

To establish a baseline for assessing the drag reduction performance of the various addon devices, the body-axis drag coefficient, $C_{A}$, is first measured for vehicle configurations in which no devices are installed. The resulting drag curves for the three baseline configurations (DC/SF, DC/DF, LS/SF) with a $1.1 \mathrm{~m}$ tractor-trailer gap exhibit the behavior typical of that for heavy vehicles, wherein $C_{A}$ increases with increasing $\psi$ (Fig. 7a), as seen in $[5,8,9,12,13,14,15,33,34,37,38,39,40,60]$ and others. This increase in $C_{A}$ is due to several phenomena that occur as the vehicle is yawed, such as flow entrainment into the tractor-trailer gap, exposure of the trailer bogie to the free-stream flow, production of large, stream-wise vortices on the top and leeward side of the vehicle, and flow separation from the leeward side of the vehicle $[5,24,25,34,37,59,60,66]$. The DC/SF vehicle is the least 
aerodynamic of these configurations due to a combination of the steeper angle of the roof aero-shield and the exposed trailer bogie on the straight-frame trailer. However, pairing the DC tractor with the DF trailer significantly reduces the trailer underbody flow, producing a vehicle that has the least aerodynamic drag of the three baseline configurations.

The drag reduction devices are installed on these baseline configurations both individually and in combination with other devices or vehicle modifications. An example of this is the installation of trailer skirts (SK1) and a boattail (BT2) to the LS/SF configuration with a reduced tractor-trailer gap size of $0.61 \mathrm{~m}$ and revised tractor side extenders (Fig. 7b). The combination of the reduced gap size and revised side extenders result in a nearly constant offset from the baseline drag curve, while both the trailer skirts and boattail exhibit larger reductions at larger yaw angles. When applied individually, the reduced gap size/revised side extenders, trailer skirts, and boattail decrease $C_{A_{\text {wavg }}}$ by $0.016,0.062$, and 0.056 , respectively. However, when these modifications are applied in combination, the net reduction in $C_{A_{\text {wavg }}}$ is measured to be 0.142 , which is slightly greater than the sum (0.134) of their individual contributions (Fig. 7c). This effect is likely due to the fact that the reduced tractor-trailer gap size and trailer skirts decrease the amount of flow separation arising from the tractortrailer gap and trailer underbody, respectively, resulting in a thinner boundary layer on the surface of the trailer. When this thinner boundary layer approaches the boattail, the flow carries additional momentum near the surface of the trailer and is therefore better able to remain attached to the angled boattail plates, thereby producing more positive trailer base pressures. A similar observation is made by Cooper [13], who measured an increase in the performance of a boattail when it is placed downstream of a more aerodynamic fore body. The enhanced performance of a combination of devices is even more pronounced when the underbody fairing and trailer wheel fairings (UBF1 + TWF1), boattail (BT1), and gap fairing (GP1) are installed on the LS/SF configuration. In this case, the sum of the individual wind-averaged drag reductions of the devices is 0.067 , whereas their combined 
reduction is 0.098 . The majority of this non-linear behavior is due to a favorable interaction between the boattail and the trailer underbody fairing and trailer wheel fairings (Fig. 7c).

The incremental reductions in both $C_{A_{\text {wavg }}}$ and the estimated fuel usage are plotted in Figs. 8-10 for the individual gap, trailer underbody, and trailer base devices. Note that the estimated fuel savings in these figures are only for highway mileage traveled since the associated wind-averaged drag coefficient would change at slower vehicle speeds. To identify the two vehicle configurations, $c_{0}$ and $c_{1}$, that are being compared in the calculation of $\Delta C_{A_{\text {wav }}}$ in these figures, we define the following plotting notation, where $c_{0}$ and $c_{1}$ are the configurations before and after the installation of the device in question, respectively. Each of the symbols in Figs. 8-10 is divided into four quadrants representing the tractor-trailer gap (upper-left quadrant), trailer base (upper-right quadrant), trailer underbody that is upstream of the trailer bogie (lower-left quadrant), and trailer underbody that is downstream of the trailer bogie (lower-right quadrant). If one or more devices or modifications are present on the $c_{0}$ vehicle, one or more of the corresponding quadrants are shaded solid. The quadrant location of the device that is being installed and assessed is identified with hatch marks. For example in Fig. 8, consider the top-most circle symbol (107, bsln) in the GP1 column, corresponding to the installation of the GP1 device on the DC/SF configuration. In this case, there is no solid shading in any of the quadrants, indicating that the $c_{0}$ configuration is a baseline configuration with a $1.1 \mathrm{~m}$ tractor-trailer gap. The hatch marks in the upperleft quadrant denote the fact that the $c_{1}$ vehicle now has the GP1 device installed in the tractor-trailer gap. The corresponding value of $\Delta C_{A_{\text {wavg }}}(-0.013)$ is therefore the difference in drag between the $c_{1}$ vehicle (DC/SF with the GP1 device) and the $c_{0}$ vehicle (DC/SF with no devices) due to the effect of the GP1 device only. The annotation "107, bsln" next to the circle symbol indicates the run numbers of the $c_{1}$ and $c_{0}$ configurations, respectively. A table listing the specific devices and vehicle configurations for each of these run numbers is provided in each figure. 


\subsection{Tractor-Trailer Gap Devices}

The reductions in $C_{A_{\text {wavg }}}$ and the estimated fuel usage for the gap devices and modifications are plotted in Fig. 8. The best performing gap device/modification occurs when the tractor-trailer gap of the baseline DC/SF configuration is decreased from $1.1 \mathrm{~m}$ to 0.61 m. This leads to a reduction in $C_{A_{\text {wavg }}}$ of 0.021 and an estimated fuel savings of about 2100 $\mathrm{L} / 2.012 \times 10^{8} \mathrm{~m}$ hwy, which is comparable to the scaled wind tunnel results of Cooper [11] for a reduced tractor-trailer gap size (see Table 1). Performing the same modification to the LS/SF configuration (93, bsln) along with the installation of the revised side extenders yields a smaller (0.016) reduction in $C_{A_{\text {wavg }}}$, which is likely due to the fact that the more streamlined LS/SF has less cross-stream flow in the tractor-trailer gap to begin with than that of the DC/SF.

\subsection{Trailer Skirts}

Figure 9 shows a plot of the reductions in $C_{A_{\text {wavg }}}$ and the estimated fuel usage as a function of the incremental skirt area, $\Delta A_{\text {skirt }}$, for the various trailer skirt devices. Although the plot contains data from the three different vehicle configurations (DC/SF, DC/DF, $\mathrm{LS} / \mathrm{SF}$ ), the collective values of $-\Delta C_{A_{\text {wavg }}}$ all increase in a nominally linear fashion with $\Delta A_{\text {skirt }}$. Cooper [13], Cooper \& Leuschen [15], and Schoon \& Pan [55] also measure an increase in $-\Delta C_{A_{\text {wavg }}}$ with increasing skirt area, though the increase in area is accomplished by independently increasing either the skirt height or length. A linear curve fit to the data in Fig. 9 yields the expression

$$
-\Delta C_{A_{\text {wavg }}}=9.31 \times 10^{-3} \Delta A_{\text {skirt }}-8.39 \times 10^{-3}
$$

where $\Delta A_{\text {skirt }}$ is in the units of $\mathrm{m}^{2}$.

In addition, a number of noteworthy trends can be identified from the plot in Fig. 9. First, it is evident that while the baseline DC/DF configuration has a reduced ground clearance 
due to the drop-deck design of the trailer $(0.65 \mathrm{~m}$ from the ground to the trailer underside compared to $1.1 \mathrm{~m}$ for the SF trailer), the installation of skirts $(134,136)$ both upstream (SK8) and downstream (TWSK3) of the bogie nevertheless leads to a reduction in $C_{A_{\text {wavg }}}$ (-0.024) and the estimated fuel usage $\left(-2400 \mathrm{~L} / 2.012 \times 10^{8} \mathrm{~m}\right.$ hwy). Next, although the trailer wheel skirts (TWSK1 + TWSK2-67, bsln) leave a sizeable portion of the underbody open on SF trailer, this skirt design reduces $C_{A_{\text {wavg }}}$ by an amount comparable to that of skirts that span nearly the entire distance between the trailer landing gear and wheels (SK5A—71, bsln; SK3 - 78, bsln). Such a design may provide the advantage of allowing easier access to the trailer underbody for the inspection of brakes and tires or for the storage of tire snow chains, while still producing an estimated fuel savings of about $3500 \mathrm{~L} / 2.012 \times 10^{8} \mathrm{~m}$ hwy. The series of runs for the SK5A (71, bsln), SK5B (72, bsln), SK5C_0.4m (73, bsln), and SK5C_0.2m $(74$, bsln $)$ skirts identify the changes in $-\Delta C_{A_{\text {wavg }}}$ that result when a single trailer skirt is sequentially modified by first extending its height from $0.9 \mathrm{~m}$ (71, bsln) to $1.0 \mathrm{~m}(72, \mathrm{bsln})$, then increasing the upstream area of the skirt by $1.0 \mathrm{~m}^{2}$ (73, bsln), and finally reducing the distance from the front edge of the skirt to the trailer side from 0.4 to $0.2 \mathrm{~m}(74, \mathrm{bsln})$. Each of these changes yields an improvement in the skirt performance, though the largest incremental changes in $-\Delta C_{A_{\text {wavg }}}$ during this sequence correspond to the first and third modifications. Applying this final skirt design (SK5C_0.2m) to the DC/SF configuration $\left(105\right.$, bsln) yields an even larger value of $-\Delta C_{A_{\text {wavg }}}$, highlighting the sensitivity of skirt performance to the tractor geometry. The resulting reductions in both $C_{A_{\text {wavg }}}(-0.076)$ and the estimated fuel usage $(-7500 \mathrm{~L} / 2.012 \times 10 \mathrm{~m}$ hwy) for this configuration (105, bsln) are the largest of any individual device evaluated in the present study. In addition, this estimated fuel savings is slightly larger than the average value $\left(\approx 5000 \mathrm{~L} / 2.012 \times 10^{8} \mathrm{~m}\right.$ hwy $)$ of the previously tested skirts shown in Table 2. Lastly, it is interesting to note that even though the trailer skirt SK2 has a value of $A_{\text {skirt }}$ nearly equal to that of skirt SK5C_0.2m $\left(6.8 \mathrm{~m}^{2}\right.$ versus $\left.6.9 \mathrm{~m}^{2}\right)$, the $\mathrm{SK} 2$ skirt yields a significantly smaller reduction in $C_{A_{\text {wavg }}}$ when 
a performance comparison is made on the DC/SF configuration (105, bsln versus 119, bsln). The primary differences between these two skirts is that the SK5C_0.2m skirt is angled relative to the trailer side and has a height of $1.0 \mathrm{~m}$, while the $\mathrm{SK} 2$ skirt is parallel to the trailer side and has a height of $0.8 \mathrm{~m}$. This once again demonstrates that slight variations in design can yield substantial changes to the skirt performance, which in this case lead to a difference in the estimated fuel savings of approximately $3000 \mathrm{~L} / 2.012 \times 10^{8} \mathrm{~m}$ hwy between the two skirts.

\subsection{Trailer Boattails}

The values of $-\Delta C_{A_{\text {wavg }}}$ for three of the boattail devices are plotted as a function of the boattail angle, $\theta$, in Fig. 10. As $\theta$ is increased from $0^{\circ}$ to $20^{\circ}$ on the BT4 boattail (DC/DF configuration), which has plates on the top and sides of the trailer base, $-\Delta C_{A_{\text {wavg }}}$ increases to a maximum value before steadily decreasing. Fitting a second-order polynomial to the BT4 boattail data demonstrates that the maximum occurs at $\theta$ about equal to $11 \pm 2^{\circ}$. This angle is comparable to a number of the optimum boattail angles found within previous studies, despite the differences in the Reynolds number, vehicle geometry, boattail length, or number of boattail plates $[3,12,13,22,26,42,55]$. The two other boattails, BT1 and BT2, have fixed angles of approximately $12^{\circ}$ and $9^{\circ}$, respectively. A comparison of runs 84 , bsln and runs 95, 94 shows the enhanced performance of the BT2 boattail when additional drag reduction devices or modifications are made upstream of the trailer base. A similar result is observed for the BT1 boattail (54, bsln or 80, bsln vs. 79, 78). By removing the bottom, horizontal boattail plate from this boattail, it is possible to assess the influence of the plate on the drag reduction performance of the BT1 boattail (54, bsln or 80, bsln vs. 81, bsln). This modification subsequently leads to a larger value of $-\Delta C_{A_{\text {wavg }}}$, though it should be noted that the change in $-\Delta C_{A_{\text {wavg }}}$ between the three and four-sided configurations is comparable to the measurement error. This possible trend is the opposite to that in the study of Cooper [13], who showed that a four-sided boattail yields a slightly larger reduction 
in the wind-averaged drag coefficient than a three-sided one. A variable-angle boattail, BT3, is also installed on the $\mathrm{DC} / \mathrm{SF}$ configuration along with several other drag reduction devices $\left(0.61 m_{-g a p}+\right.$ SK1 + TWSK1 + TWSK2) (Fig. 11). Since no measurements are made for this specific configuration less the BT3 boattail, the values of $-\Delta C_{A_{\text {wavg }}}$ are calculated relative to a baseline $\mathrm{DC} / \mathrm{SF}$ configuration with a $1.1 \mathrm{~m}$ tractor-trailer gap. Most notably, the optimum boattail deflection angle is about equal to that shown previously for the BT4 boattail, in spite of the fact that the trailer geometry and boattail height differ. Combined with the contributions from the gap modification and the trailer skirt devices, the resulting optimum value of $-\Delta C_{A_{\text {wavg }}}$ is approximately 0.14 , which is equivalent to a savings in the estimated fuel usage of nearly $14000 \mathrm{~L} / 2.012 \times 10^{8} \mathrm{~m}$ hwy.

\subsection{Device Performance Summary}

The changes in $-\Delta C_{A_{\text {wav }}}$ for all of the drag reduction devices, installed either individually or in combination with other devices, are plotted in Figs. 12-14 relative to the corresponding baseline DC/SF, LS/SF, or DC/DF configurations, respectively. For the LS/SF configuration, the top performing individual devices are both trailer skirts (SK1 - run 82; SK5C_0.2m-run74), each of which yields a value of $-\Delta C_{A_{\text {wavg }}}$ equal to 0.062 or an estimated fuel savings of approximately $6000 \mathrm{~L} / 2.012 \times 10^{8} \mathrm{~m}$ hwy. The largest drag reduction $\left(-\Delta C_{A_{\text {wav }}}=0.144\right)$ for the LS/SF configuration occurs for the simultaneous installation of the SK1 and TWSK1 skirts and the BT2 boattail along with a reduced tractor-trailer gap size of $0.61 \mathrm{~m}$ and the revised tractor side extenders. The resulting estimated fuel savings is approximately $14000 \mathrm{~L} / 2.012 \times 10^{8} \mathrm{~m}$ hwy. An even larger reduction in drag $\left(-\Delta C_{A_{\text {wavg }}}\right.$ $=0.150)$ occurs when the same skirts and boattail are installed on the DC/SF configuration with a $0.61 \mathrm{~m}$ tractor-trailer gap, which is completely covered on both the driver and passenger sides. In this case, the estimated fuel savings is calculated to be nearly 15000 $\mathrm{L} / 2.012 \times 10^{8} \mathrm{~m}$ hwy, which is the largest of the entire study and comparable to the scaled wind tunnel data of Cooper [13] for a similar combination of devices. 


\section{Discussion}

While it is apparent that there is a great potential for fuel savings through the use of aerodynamic drag reduction devices, the commercial fleet operators responsible for purchasing them take into account a number of additional factors before they consider these devices to be a truly viable means for cost savings. Therefore, in addition to the wind tunnel investigation, we conducted a survey from August to September 2010 of 256 small and large fleet companies and owner/operater companies that operate class 8 heavy vehicles in the United States (we define a small fleet as one in which there are at most 25 tractor-trailers and a large fleet as one in which there are more than 26 tractor-trailers). A number of questions are asked of these fleets to better understand their past experiences with drag reduction devices, to determine the criteria and requirements the devices would have to meet in order to have them installed throughout the majority of their fleets, and to further improve the design of the devices. The feedback from this survey along with device performance data will be essential as we move towards our goal of designing a trailer with factory-installed devices that are both effective in reducing aerodynamic drag and acceptable by the fleet operators who purchase them.

From the results of the survey, only $5 \%$ of the companies are currently using tractortrailer gap devices and trailer base devices, while $4 \%$ are using trailer skirts. However, 2-7\% of the companies are planning to use these various devices in their operations and another 27-30\% would consider using them within the next 12 months to increase their fleet fuel economy and reduce fuel costs. Most notably, the majority of the companies currently using drag reduction devices observe an increase in vehicle fuel economy comparable to that which was expected when the devices were purchased. Additional benefits that result from the installation of these devices are reported to be improved vehicle handling under windy conditions and a reduction in the amount of debris and water spray ejected by the vehicle, the latter of which is similar to the findings of Weir et al. [66]. 
In spite of these benefits, a number of shortcomings and challenges are identified with the current drag reduction devices on the market. The purchase price is found to be the primary barrier that prevents the adoption of these devices. About half of the companies are willing to spend only $\$ 1000$ or less on aerodynamic devices for each tractor-trailer combination, while $29 \%$ will spend only $\$ 500$ or less. At the time of this survey, the former cost requirement prevents all of the commercially available trailer skirts and base devices evaluated in the $80 \times 120$ wind tunnel from being viable options for nearly half of the companies surveyed. In addition, the payback time for the devices is required to be 1 to 2 years for about half of the companies and 3 years for another third of the companies. Second, the durability of the devices is another shortcoming that must be met given that two-thirds of the companies expect to spend only 5 hours or less per trailer each year for aerodynamic device maintenance. And it is a lack of device durability, increased maintenance costs, vehicle downtime, and a lack of device service stations for long-haul fleets that have often caused a number of companies to discontinue the use of certain devices. Third, since a number of fleets operate their vehicles up to a maximum load capacity, the weight of the devices can also prohibit the fleets from employing them. In fact, about one-half of the surveyed companies are willing to add only 68 $\mathrm{kg}(149 \mathrm{lb})$ or less to their vehicles. Except for the gap devices, this requirement eliminates nearly all of the commercially available trailer skirt and base devices evaluated in this study. Lastly, the design of the device and its manner of deployment presents a challenge to the fleets from both operational and cost standpoints. More than two-thirds of the companies prefer that the aerodynamic devices deploy in a fully automatic fashion in order to eliminate driver errors and to decrease the possibility of accidents or injuries. However, the convenience of automatic deployment comes with additional device complexity, which reduces reliability and increases the purchase price and maintenance time of the device. For about one-quarter of the companies, this disadvantage is too costly and they would rather have their drivers manually deploy devices that are simpler in construction and much easier to repair. 
These concerns and issues must first be addressed before aerodynamic drag reduction devices can be accepted on a widespread basis throughout the United States. Both mass production of devices and government tax breaks for fleets utilizing them can reduce the purchase price barrier, making the devices affordable for a greater number of companies. To provide device maintenance for long-haul trailers that are traveling cross-country, nationwide service centers that presently repair tires or tractors can be trained and equipped to also repair aerodynamic devices. Furthermore, improved designs can minimize the weight penalty of the devices and increase their durability. An example of the latter can be seen in the evolution of trailer skirts, which originally had designs that were often constructed from aluminum sheet metal. While aluminum is corrosion resistant and lightweight, it is unforgiving when flexed beyond a certain point. To remedy this shortcoming, a number of trailer skirt manufacturers have started to use deformable, plastic panels that are attached to the trailer underside in a manner that allows the skirt to flex without permanent deformation when it contacts the ground.

The question of whether or not the devices should be manually or automatically deployed remains to be answered. Perhaps, one solution is to integrate the device completely into the trailer design, such that deployment is not even necessary. An example of this is seen in the work of Schoon [54], wherein a prototype trailer is designed with an integrated boattail shape along the last $0.61 \mathrm{~m}$ of the trailer. With the boattail constructed in a structural manner similar to that of a standard trailer, it is robust enough to withstand operational mishaps, such as accidental backing into a loading dock. The aerodynamic drag due to the tractor-trailer gap can also be reduced with an automated fifth-wheel that is integrated into the tractor. At highway speeds, where vehicle maneuvering is minimal, the fifth-wheel would automatically decrease the distance between the tractor and trailer, while, below a certain speed, the fifth wheel would increase this distance to allow for pivotal motion between the tractor and trailer. Such a system would require no driver intervention, though it would 
need to be designed for both safe and reliable operation without significantly increasing the cost of the tractor.

\section{Conclusions}

Through this experimental study, we have investigated the performance of drag reduction devices for modern class 8 heavy vehicles. Wind tunnel measurements are made on three full-scale heavy vehicle configurations, which are comprised of a long sleeper tractor with a straight-frame trailer, a day-cab tractor with a straight-frame trailer, and a day-cab tractor with a drop-frame trailer. The devices are installed in the tractor-trailer gap and trailer underbody and base in order to alleviate the drag sources arising from these portions of the vehicle. While the gap fairings provide a reduction in the vehicle drag, the most effective gap modification for the two straight-frame trailer configurations is found to be a reduced tractor-trailer gap size of $0.61 \mathrm{~m}$. For these two cases, the wind-averaged drag coefficient is reduced by 0.016 and 0.021 , yielding an estimated fuel savings of about 1600 and 2100 $\mathrm{L} / 2.012 \times 10^{8} \mathrm{~m}$ of highway mileage driven. Larger reductions in drag are achieved through the installation of a boattail on the trailer base. For the two fixed angle boattails, the wind-averaged drag coefficient is reduced by 0.047 to 0.056 when the boattails are installed without any other devices. The corresponding fuel savings is about 4600 to $5500 \mathrm{~L} / 2.012 \times 10^{8}$ $\mathrm{m}$ of highway mileage driven. The boattail performance is enhanced when drag reduction devices are installed upstream of the trailer base. The largest reduction in drag for a single device arises from one of the trailer skirts, which yields a decrease in the wind-averaged drag coefficient and the estimated fuel use of 0.076 and about $7500 \mathrm{~L} / 2.012 \times 10^{8} \mathrm{~m}$ of highway mileage driven, respectively, for the day-cab tractor with a straight-frame trailer. When the devices are simultaneously installed on the tractor-trailer gap and trailer underbody and base, the drag reduction is even greater, resulting in estimated fuel savings of about 15000, 14000, and $10000 \mathrm{~L} / 2.012 \times 10^{8} \mathrm{~m}$ of highway mileage driven for the day-cab tractor with 
the straight-frame trailer, the long sleeper tractor with the straight-frame trailer, and the day-cab tractor with the drop-frame trailer, respectively.

While this study has successfully highlighted the aerodynamic performance of a wide range of drag reduction devices, there are two important matters that remain to be determined at the present time. The first is the actual fuel savings provided by these devices during normal operations. Since the data from this study has been acquired in a very controlled environment, it may not be entirely representative of the flow fields that heavy vehicles encounter when travelling on the road. For example, the wind tunnel does not produce the freestream unsteadiness and turbulent length scales that arise from an environmental flow and its interactions with roadside objects and nearby vehicles. In addition, the non-moving ground plane beneath the vehicle produces a boundary layer that may underestimate the performance of the trailer underbody devices. As has been observed in previous studies, these types of effects can lead to differences between the estimated fuel savings from wind tunnel data and that actually observed on the road $[4,5,6,16,29,50,65]$. To remedy this potential shortcoming, future studies will include fuel economy data from both track testing and subsequent fleet evaluations of select devices. The second matter that remains to be determined is properly addressing the concerns raised by fleets regarding the drag reduction devices. From the results of the fleet survey, it is clearly evident that a number of the devices evaluated within this study are simply unacceptable to the fleets due to numerous economic, weight, and durability issues. As we move forward on this project, we will work closely with our fleet and third-party device manufacturer team members to develop robust, operationally-minded, and cost-effective solutions to these concerns. This process will provide a definitive path to implementing the drag reduction devices into future trailers, thereby providing viable options for fleets seeking to improve the fuel economy of their heavy vehicle operations. 


\section{Acknowledgments}

The authors would like to thank M. Betzina, C. Hartley, S. Lee, J. Sacco, and the entire National Full-Scale Aerodynamics Complex team for their support during the wind tunnel testing, J. Martinez and R. Flach of Texas A\&M University for their wind tunnel testing guidance and expertise, S. Baker, B. Hirschy, A. Spieth, and V. Swager of Navistar for their mechanic support, E. Buckholtz, J. King, and S. LaMunyon of LLNL for their support in device fabrication, the device manufacturers for loaning their gap fairings, trailer skirts, and boattails, and F. Browand of the University of Southern California and P. Urbanczyk of LLNL for their helpful feedback in the manuscript preparation. Lastly, the authors would like to thank Lee Slezak of the Department of Energy Vehicle Technologies Program for his programmatic support of this research effort. This work was performed under the auspices of the US DOE by LLNL under contract DE-AC52-07NA27344.

\section{References}

[1] Annual Energy Outlook 2010 with Projections to 2035. 2010. DOE/EIA-0383(2010).

[2] Bachman, L.J., Erb, A., Bynum, C.L., 2005. Effect of single wide tires and trailer aerodynamics on fuel economy and NOx emissions of class 8 line-haul tractor-trailers. SAE Paper 05CV-45.

[3] Browand, F., Radovich, C., Boivin, M., 2005. Fuel savings by means of flaps attached to the base of a trailer: field test results. SAE Paper 2005-01-1016.

[4] Buckley, F.T., Jr., Marks, C.H., Walston, W.H., Jr., 1976. Analysis of coast down data to assess aerodynamic drag reduction on full-scale tractor-trailer trucks in windy environments. SAE Trans. 85, 2756-2769.

[5] Buckley, F.T., Jr., Marks, C.H., Walston, W.H., Jr., 1978. A study of aerodynamic methods for improving truck fuel economy. Final Report on National Science Foundation, 
Grant No. SIA-74-14843. Mechanical Engineering Department, University of Maryland, College Park, MD.

[6] Buckley, F.T., Jr., Walston, W.H., Jr., Marks, C.H., 1978. Fuel savings from truck aerodynamic drag reducers and correlation with wind-tunnel data. J. Energy 2(6), 321-329.

[7] Coon, J.D., Visser, K.D., 2004. Drag reduction of a tractor-trailer using planar boat tail plates, in: McCallen, R., Browand, F., Ross, J., (Eds.), The Aerodynamics of Heavy Vehicles: Trucks, Buses, and Trains, Lecture Notes in Applied and Computational Mechanics 19. Springer, Heidelberg, pp. 249-265.

[8] Cooper, K.R., 1976. A wind tunnel investigation into the fuel savings available from the aerodynamic drag reduction of trucks. National Research Council Canada, Reprint of article from DME/NAE Quarterly Bulletin, No. 1976(3).

[9] Cooper, K.R., 1978. Truck fuel savings through the use of trailer skirts and trailer rearcorner rounding. National Research Council Canada, LTR-LA-224.

[10] Cooper, K.R., Mason, W.T., Jr., Bettes, W.H., 1982. Correlation experience with the SAE wind tunnel test procedure for trucks and buses. SAE Paper 820375.

[11] Cooper, K.R., 1982. The wind tunnel testing of heavy trucks to reduce fuel consumption. SAE Paper 82185.

[12] Cooper, K.R., 1985. The effect of front-edge rounding and rear-edge shaping on the aerodynamic drag of bluff vehicles in ground proximity. SAE Paper 850288.

[13] Cooper, K.R., 2003. Truck aerodynamics reborn-lessons from the past. SAE Paper 2003-01-3376.

[14] Cooper, K.R., 2004. Commercial vehicle aerodynamic drag reduction: historical perspective as a guide, in: McCallen, R., Browand, F., Ross, J., (Eds.), The Aerodynamics of 
Heavy Vehicles: Trucks, Buses, and Trains, Lecture Notes in Applied and Computational Mechanics 19. Springer, Heidelberg, pp. 9-28.

[15] Cooper, K.R., Leuschen, J., 2005. Model and full-scale wind tunnel tests of secondgeneration aerodynamic fuel saving devices for tractor-trailers. SAE Paper 2005-01-3512.

[16] Davis, W.R., Eryou, N.D., Patry, J.C., 1977. Operational road tests of truck aerodynamic drag reduction devices. SAE Paper 770690.

[17] Davis, S.C., Diegel, S.W., Boundy, R.G., 2010. Transportation Energy Data Book, Edition 29. ORNL-6985.

[18] Englar, R.J., 2004. Pneumatic heavy vehicle aerodynamic drag reduction, safety enhancement, and performance improvement, in: McCallen, R., Browand, F., Ross, J., (Eds.), The Aerodynamics of Heavy Vehicles: Trucks, Buses, and Trains, Lecture Notes in Applied and Computational Mechanics 19. Springer, Heidelberg, pp. 277-302.

[19] Englar, R.J., Improved pneumatic aerodynamics for drag reduction, fuel economy, safety and stability increase for heavy vehicles. SAE Paper 2005-01-3627, 2005.

[20] Figliola, R.S., Beasley, D.E., 1995. Theory and Design for Mechanical Measurements, 2nd Edition. John Wiley \& Sons, Inc., New York.

[21] Flynn, H., Kyropoulos, P., 1962. Truck aerodynamics. SAE Paper 620531.

[22] Grover, K., Visser, K.D., 2006. Over-the-road tests of sealed aft cavities on tractor trailers. SAE Paper 2006-01-3529.

[23] Gutierrez, W.T., Hassan, B., Croll, R.H., Rutledge, W.H., 1996. Aerodynamics overview of the ground transportation systems (GTS) project for heavy vehicle drag reduction. SAE Paper 960906. 
[24] Hammache, M., Browand, F., 2004. On the aerodynamics of tractor-trailers, in: McCallen, R., Browand, F., Ross, J., (Eds.), The Aerodynamics of Heavy Vehicles: Trucks, Buses, and Trains, Lecture Notes in Applied and Computational Mechanics 19. Springer, Heidelberg, pp. 185-205.

[25] Heineck, J.T., Walker, S.M., Satran, D., 2004. The measurement of wake and gap flows of the generic conventional truck model (GCM) using three-component PIV, in: McCallen, R., Browand, F., Ross, J., (Eds.), The Aerodynamics of Heavy Vehicles: Trucks, Buses, and Trains, Lecture Notes in Applied and Computational Mechanics 19. Springer, Heidelberg, pp. 173-184.

[26] Hsu, T.-Y., Hammache, M., Browand, F., 2004. Base flaps and oscillatory perturbations to decrease base drag, The Aerodynamics of Heavy Vehicles: Trucks, Buses, and Trains, in: McCallen, R., Browand, F., Ross, J., (Eds.), Lecture Notes in Applied and Computational Mechanics 19. Springer, Heidelberg, pp. 303-316.

[27] Ingram, K.C., 1978. The wind-averaged drag coefficient applied to heavy goods vehicles. Transportation and Road Research Laboratory, TRRL Supplementary Report 392.

[28] Kelton-Fogg, G., 1979. Aerodynamic drag reduction devices in the trucking industry: a market study. SRI Project 7171, Contract NAS 2-9846.

[29] Kettinger, J.N., 1982. Tractor-trailer fuel savings with an aerodynamic device-a comparison of wind tunnel and on-road tests. SAE Paper 820376.

[30] Laflamme, R., 2009. A fleet operator's perspective on commercial vehicle drag reduction, in: McCallen, R.C., Browand, F., Ross, J., (Eds.), The Aerodynamics of Heavy Vehicles II: Trucks, Buses, and Trains, Lecture Notes in Applied and Computational Mechanics 41. Springer, Heidelberg, pp. 463. 
[31] Lanser, W.R., Ross, J.C., Kaufman, A.E., 1991. Aerodynamic performance of a drag reduction device on a full-scale tractor/trailer. SAE Paper 912125.

[32] Leuschen, J. and Cooper, K.R., 2006. Full-scale wind tunnel tests of production and prototype, second-generation aerodynamic drag-reducing devices for tractor-trailers. SAE Paper 06CV-222.

[33] Lissaman, P.B.S. (Ed.), 1974. Reduction of the Aerodynamic Drag of Trucks. Conference/Workshop Proceedings, California Institute of Technology, Pasadena, CA, October $10-11$.

[34] Mason, W.T., Beebe, P.S., 1978. The drag related flow field characteristics of trucks and buses, in: Sovran, G., Morel, T., Mason, W.T., Jr. (Eds.), Aerodynamic Drag Mechanisms of Bluff Bodies and Road Vehicles. Plenum Press, pp. 45-90.

[35] McCallen, R.C., et al., 2000. Aerodynamic drag of heavy vehicles (class 7-8): simulation and benchmarking. SAE Paper 2000-01-2209.

[36] Montoya, L.C., Steers, L.L., 1974. Aerodynamic drag reduction tests on a full-scale tractor-trailer combination with several add-on devices. NASA TM X-56028.

[37] Muirhead, V.U., 1978. An investigation of drag reduction for tractor trailer vehicles. NASA Contractor Report 144877.

[38] Muirhead, V.U., Saltzman, E.J., 1979. Reduction of aerodynamic drag and fuel consumption for tractor-trailer Vehicles. J. Energy, 3(5), 279-284.

[39] Muirhead, V.U., 1981. An investigation of drag reduction for tractor trailer vehicles with air deflector and boattail. NASA Contractor Report 163104.

[40] Nakaguchi, H., 1978. Recent Japanese research on three-dimensional bluff-body flows relevant to road-vehicle aerodynamics, in: Sovran, G., Morel, T., Mason, W.T., Jr. (Eds.), 
Aerodynamic Drag Mechanisms of Bluff Bodies and Road Vehicles. Plenum Press, pp. 227246.

[41] Nayeri, C.N., et al., 2009. Drag reduction on a generic tractor-trailer using active flow control in combination with solid flaps, in: McCallen, R.C., Browand, F., Ross, J., (Eds.), The Aerodynamics of Heavy Vehicles II: Trucks, Buses, and Trains, Lecture Notes in Applied and Computational Mechanics 41. Springer, Heidelberg, pp. 179-191.

[42] Ortega, J.M., Salari, K., 2004. An experimental study of drag reduction devices for a trailer underbody and base. Paper AIAA-2004-2252.

[43] Ortega, J., Salari, K,. Storms, B., 2009. Investigation of tractor base bleeding for heavy vehicle aerodynamic drag reduction, in: McCallen, R.C., Browand, F., Ross, J. (Eds.), The Aerodynamics of Heavy Vehicles II: Trucks, Buses, and Trains, Lecture Notes in Applied and Computational Mechanics 41. Springer, Heidelberg, pp. 161-178.

[44] Peterson, R.L., 1981. Drag reduction obtained by the addition of a boattail to a box shaped vehicle. NASA Contractor Report 163113.

[45] Radovich, C.A., 2005. Wind tunnel test of cab extender incidence on heavy truck aerodynamics. SAE Paper 2005-01-3527.

[46] Ritchie, D., 1973. Beat the built-in headwind. Commercial Car Journal, September.

[47] Saltzman, E.J., Meyer, R.R., Jr., 1974. Drag reduction obtained by rounding vertical corners on a box-shaped vehicle. NASA TM X-56023.

[48] Saltzman, E.J., 1982. A summary of NASA Dryden's truck aerodynamic research. SAE Paper 821284 .

[49] Saltzman, E.J., Meyer, R.R., Jr., 1999. A Reassessment of heavy-duty truck aerodynamic design features and priorities. NASA/TP-1999-206574. 
[50] Saunders, J.W., Watkins, S., Hoffmann, P.H., Buckley, F.T., Jr., 1985. Comparison of on-road and wind-tunnel tests for tractor-trailer aerodynamic devices, and fuel savings predictions. SAE Paper 850286,

[51] Seifert, A., et al., 2009. Large trucks drag reduction using active flow control, in: McCallen, R.C., Browand, F., Ross, J., (Eds.), The Aerodynamics of Heavy Vehicles II: Trucks, Buses, and Trains, Lecture Notes in Applied and Computational Mechanics 41. Springer, Heidelberg, pp. 115-133.

[52] Seifert, A., Horrell, C., Grossmann, J., Smith, A., 2010. Heavy trucks fuel savings using the SaOB actuator (abstract). The Aerodynamics of Heavy Vehicles: Trucks, Buses, and Trains III. Potsdam, Germany, September 12-17.

[53] Servais, R.A., Bauer, P.T., 1975. Aerodynamic devices can significantly reduce the fuel consumption of trucks: experience with CECA designs. SAE Paper 750707.

[54] Schoon, R.E., 2007. On-road evaluation of devices to reduce heavy truck aerodynamic drag. SAE Paper 2007-01-4294.

[55] Schoon, R., Pan, F.P., 2007. Practical devices for heavy truck aerodynamic drag reduction. SAE Paper 2007-01-1781.

[56] Sovran, G., Morel, T., Mason, W.T., Jr., 1978. Aerodynamic Drag Mechanisms of Bluff Bodies and Road Vehicles. Plenum Press, New York-London.

[57] Steers, L.L., Montoya, L.C., Saltzman, E.J., 1975.. Aerodynamic drag reduction tests on a full-scale tractor-trailer combination and a representative box-shaped ground vehicle. SAE Paper 750703.

[58] Steers, L.L., Saltzman, E.J., 1977. Reduced truck fuel consumption through aerodynamic design. J. Energy 1(5), 312-318. 
[59] Storms, B.L., Ross, J.C., Heineck, J.T., Walker, S.M., Driver, D.M., Zilliac, G.G., 2001. An experimental study of the ground transportation system (GTS) model in the NASA Ames 7- by 10-ft wind tunnel. NASA/TM-2001-209621.

[60] Storms, B.L., Satran, D.R., Heineck, J.T., Walker, S.M., 2004. A study of Reynolds number effects and drag-reduction concepts on a generic tractor-trailer. Paper AIAA2004-2251.

[61] Storms, B.L., Satran, D.R., Heineck, J.T., Walker, S.M., 2005. Detailed experimental results of drag-reduction concepts on a generic tractor-trailer. SAE Paper 2005-01-3525.

[62] Surcel, M.-D., Michaelsen, J., Provencher, Y., 2008. Track-test evaluation of aerodynamic drag reducing measures for class 8 tractor-trailers. SAE Paper 2008-01-2600.

[63] Taubert, L., Wygnanski, I., 2009. Preliminary experiments applying active flow control to a $1 / 24^{\text {th }}$ scale model of a semi-trailer truck, in: McCallen, R.C., Browand, F., Ross, J., (Eds.), The Aerodynamics of Heavy Vehicles II: Trucks, Buses, and Trains, Lecture Notes in Applied and Computational Mechanics 41. Springer, Heidelberg, pp. 105-113,

[64] Walston, W.H., Jr., Buckley, F.T., Jr., Marks, C.H., 1976. Test procedures for the evaluation of aerodynamic drag on full-scale vehicles in windy environments. SAE Paper 760106.

[65] Watkins, S., Cooper, K.R., 2007. The unsteady wind environment of road vehicles, part two: effects on vehicle development and simulation of turbulence. SAE Paper 2007-011237,

[66] Weir, D.H., Strange, J.F., Heffley, R.K., 1978. Reduction of adverse aerodynamic effects of large trucks. Federal Highway Administration Report FHWA-RD-79-84.

[67] Zell, P.T., 1993. Performance and test section flow characteristics of the National FullScale Aerodynamics Complex 80- by 120-foot wind tunnel. NASA TM 103920. 


\begin{tabular}{|c|c|c|c|c|}
\hline Investigators & Ref. \# & Test method & $\begin{array}{l}\text { Fuel savings } \\
\left(\mathrm{L} / 2.012 \times 10^{8} \mathrm{~m} \text { hwy }\right)\end{array}$ & Remarks \\
\hline Cooper & [9] & SWT & 3978 & Full GS \\
\hline Cooper & [11] & SWT & 2253 & Reduced gap $(1.5 \mathrm{~m}$ to $1.0 \mathrm{~m})$ \\
\hline Cooper & [11] & SWT & 3219 & GS \\
\hline Cooper & [11] & SWT & 5151 & Filled gap, sides \& top \\
\hline Cooper & [11] & SWT & 3863 & $\mathrm{SE}$ \\
\hline Cooper & [13] & SWT & 2556 & Full GS \\
\hline Cooper, et al. & [15] & SWT & 2082 & $0.25 \mathrm{~m} \mathrm{SE}$ \\
\hline Cooper, et al. & [15] & SWT & 3029 & $0.51 \mathrm{~m} \mathrm{SE}$ \\
\hline Cooper, et al. & [15] & SWT & 3644 & $0.76 \mathrm{~m} \mathrm{SE}$ \\
\hline Cooper, et al. & [15] & SWT & 2130 & $0.53 \mathrm{~m}$ "vortex stabilizer" \\
\hline Cooper, et al. & [15] & SWT & 2272 & $0.64 \mathrm{~m}$ "vortex stabilizer" \\
\hline Cooper, et al. & [15] & SWT & 2556 & $1.1 \mathrm{~m} \mathrm{GS}$ \\
\hline Cooper, et al. & [15] & FSWT & 5679 & "Vortex stabilizer" \\
\hline Cooper, et al. & [15] & FSWT & 7335 & SE \\
\hline Leuschen, et al. & [32] & FSWT & 1258 & Trailer nose fairing, $8.5 \mathrm{~m}$ trailer \\
\hline Leuschen, et al. & [32] & FSWT & 167 & Labryrinthine plates, $8.5 \mathrm{~m}$ trailer \\
\hline
\end{tabular}

Table 1: Summary of highway fuel savings for tractor-trailer gap devices. FSWT-full scale wind tunnel test, GS-gap seal, SE-tractor side extenders, SWT-scale wind tunnel test. Note: some studies refer to the gap seal as a "vortex stabilizer," gap splitter plate, or trailer nose fairing. 


\begin{tabular}{lllll}
\hline Investigators & Ref. \# & Test method & $\begin{array}{l}\text { Fuel savings } \\
\left(\mathrm{L} / 2.012 \times 10^{8} \mathrm{~m} \text { hwy) }\right.\end{array}$ & Remarks \\
\hline Cooper & {$[8]$} & SWT & 4865 & SK \\
Cooper & {$[9]$} & SWT & 3296 to 5286 & SK \& arched SK \\
Cooper & {$[11]$} & SWT & 3541 & SK \\
Cooper & {$[13]$} & SWT & 6909 & SK \\
Cooper & {$[13]$} & SWT & 4592 & SK \\
Cooper & {$[13]$} & SWT & 9465 & SK \& TWSK \\
Cooper & {$[13]$} & FSWT & 3691 & SK, 8.5 m trailer \\
Cooper, et al. & {$[15]$} & SWT & 2224 & Short-length SK \\
Cooper, et al. & {$[15]$} & SWT & 3502 & Mid-length SK \\
Cooper, et al. & {$[15]$} & SWT & 4401 & SK \\
Cooper, et al. & {$[15]$} & FSWT & 5206 & SK \\
Leuschen, et al. & {$[32]$} & FSWT & 4456 & SK, 8.5 m trailer \\
Leuschen, et al. & {$[32]$} & FSWT & 3645 & SK \& TWSK, 8.5 m trailer \\
Leuschen, et al. & {$[32]$} & FSWT & 3504 & SK, 8.5 m trailer \\
Leuschen, et al. & {$[32]$} & FSWT & 3420 & SK, 8.5 m trailer \\
Muirhead, et al. & {$[38]$} & SWT & 9792 & SK \\
Surcel, et al. & {$[62]$} & Track & 7827 & SK \& TWSK \\
Surcel, et al. & {$[62]$} & Track & 7384 & SK \& TWSK \\
\hline
\end{tabular}

Table 2: Summary of highway fuel savings for trailer skirts. FSWT-full-scale wind tunnel test, SK-trailer skirt, SWT-scale wind tunnel test, TWSK-trailer wheel skirt located behind the trailer bogie. 


\begin{tabular}{lllll}
\hline Investigators & Ref. \# & Test method & $\begin{array}{l}\text { Fuel savings } \\
\left(\mathrm{L} / 2.012 \times 10^{8} \mathrm{~m} \mathrm{hwy}\right)\end{array}$ & Remarks \\
\hline Browand, et al. & {$[3]$} & Track & 3320 & 3-sided BT \\
Coon, et al. & {$[7]$} & Road & 5914 & 4-sided inset BT \\
Cooper & {$[9]$} & SWT & 0 to 1307 & Trailer rear corner rounding \\
Cooper & {$[13]$} & FSWT & 2983 & 3-sided BT \\
Cooper & {$[13]$} & FSWT & 3313 & 4-sided BT \\
Cooper & {$[13]$} & Road & 2605 & 3-sided BT \\
Cooper & {$[13]$} & SWT & 3597 & 3-sided BT \\
Cooper & {$[13]$} & SWT & 4119 & 4-sided BT \\
Cooper & {$[13]$} & SWT & 3786 & 3-sided BT \\
Cooper, et al. & {$[15]$} & SWT & 4401 & 3-sided BT \\
Cooper, et al. & {$[15]$} & FSWT & 5206 & 3-sided BT \\
Grover, et al. & {$[22]$} & Road & 4338 & 4-sided BT \\
Leuschen, et al. & {$[32]$} & FSWT & 4716 & 3-sided BT, 8.5 m trailer \\
Leuschen, et al. & {$[32]$} & FSWT & 4083 & Inflatable BT, 8.5 m trailer \\
Muirhead, et al. & {$[38]$} & SWT & 4459 & Rounded BT \\
Surcel, et al. & {$[62]$} & Track & 2817 & 3-sided BT \\
\hline
\end{tabular}

Table 3: Summary of highway fuel savings for trailer base devices. BT-boattail, FSWTfull-scale wind tunnel test, SWT-scale wind tunnel test.

\begin{tabular}{lllll}
\hline Investigators & Ref. \# & Test method & $\begin{array}{l}\text { Fuel savings } \\
\left(\mathrm{L} / 2.012 \times 10^{8} \mathrm{~m} \text { hwy }\right)\end{array}$ \\
\hline Cooper & {$[9]$} & SWT & 8923 & GS \& SK \\
Cooper & {$[13]$} & SWT & 15996 & SK, TWSK, full GS, \& 3-sided BT \\
Cooper et al. & {$[15]$} & SWT & 9512 & SK, TWSK, \& 3-sided BT \\
Cooper et al. & {$[15]$} & SWT & 10175 & Mid-length SK, 0.76 m SE, \& 3-sided BT \\
Cooper et al. & {$[15]$} & SWT & 13156 & SK, TWSK, 0.76 m SE, \& 3-sided BT \\
Cooper et al. & {$[15]$} & FSWT & 12825 & Mid-length SK, 0.76 m SE, \& 3-sided BT \\
\hline
\end{tabular}

Table 4: Summary of highway fuel savings for combinations of devices. BT-boattail, GSgap seal, FSWT-full-scale wind tunnel test, SK-trailer skirt, SWT-scale wind tunnel test, TWSK-trailer wheel skirt located behind the trailer bogie. 


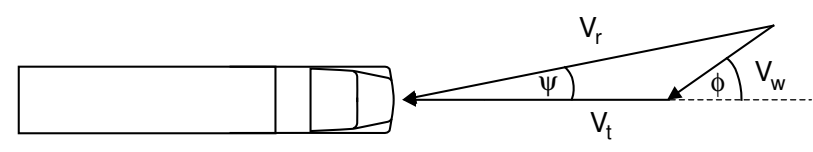

Figure 1: Wind vectors relative to the heavy vehicle. 
a)

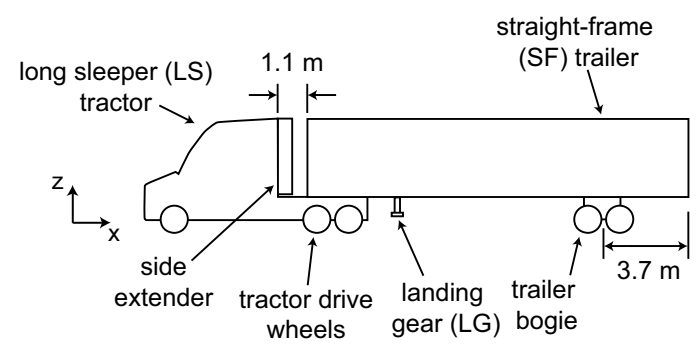

b)

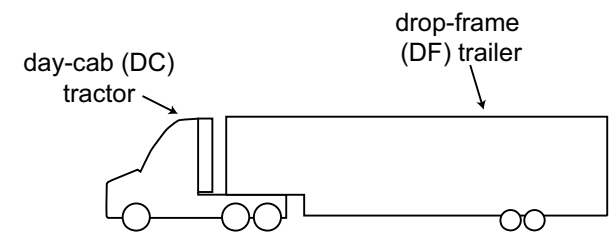

c)

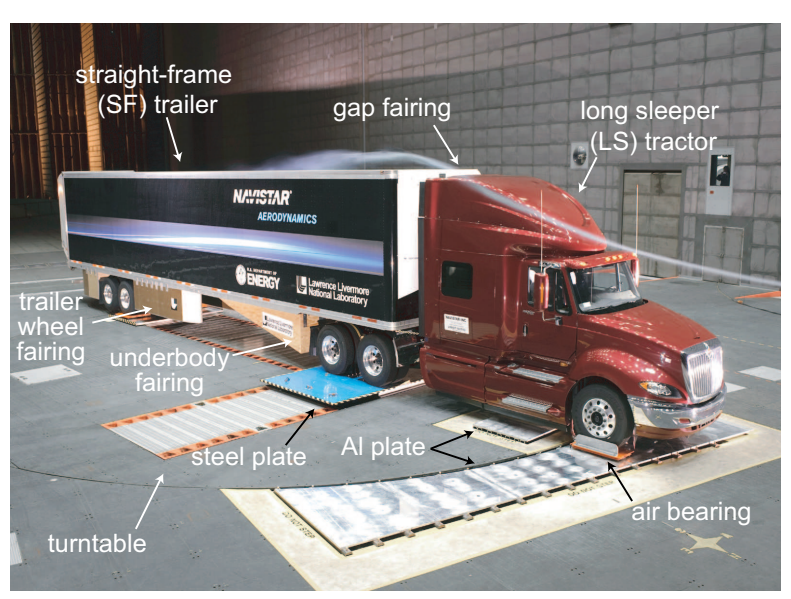

d)

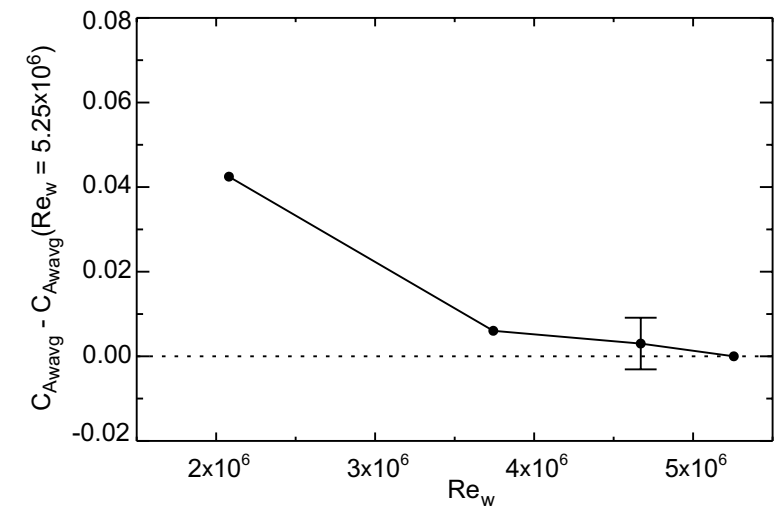

Figure 2: a) Long sleeper (LS) tractor and straight-frame (SF) trailer and b) day-cab (DC) tractor and drop-frame (DF) trailer configurations. c) LS/SF configuration mounted on the wind tunnel force balance. d) Wind-averaged drag coefficient, $C_{\text {Awavg }}$, relative to $C_{\text {Awavg }}$ at $R e_{w}=5.25 \times 10^{6}$ as a function of $R e_{w}$. 
a)

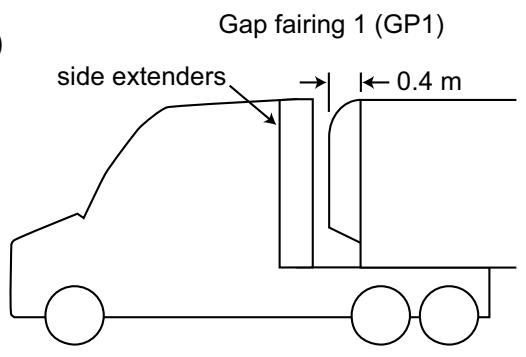

b)

Gap fairing 2 (GP2)

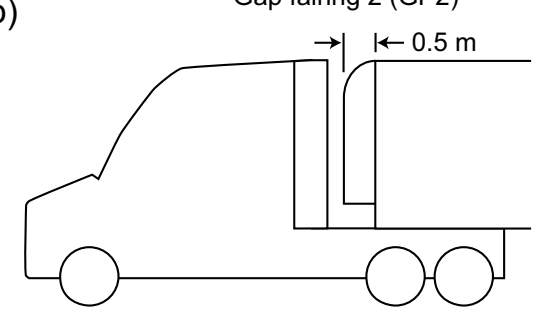

c)

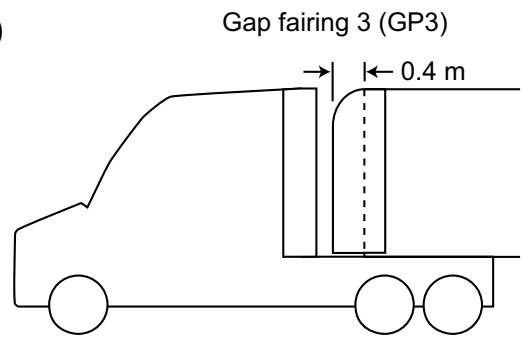

d)

Full side extenders (FULL_SE)

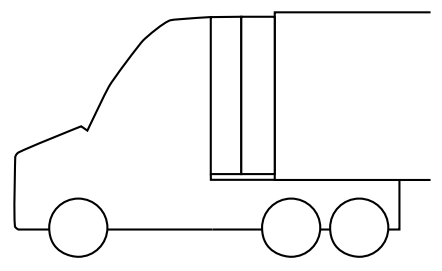

Figure 3: a-c) Fairings and d) full side extenders (FULL_SE) for the tractor-trailer gap. 
a)

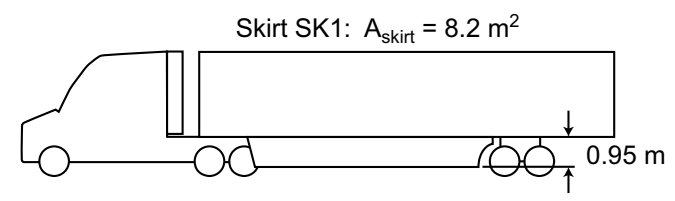

b)

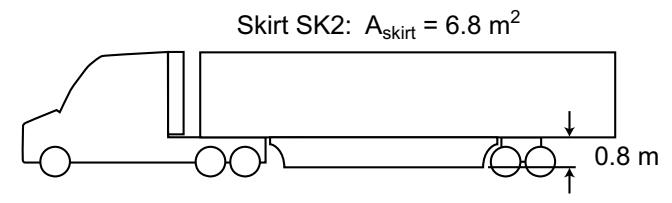

c)
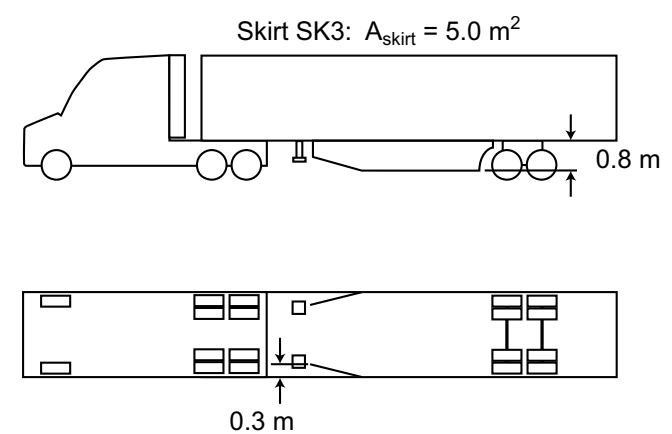

d)
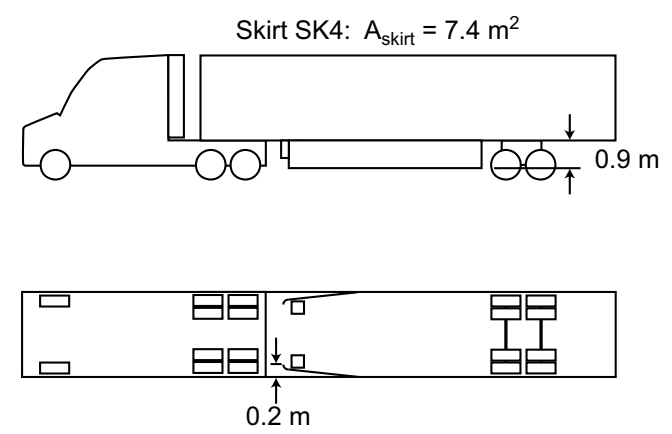

e)
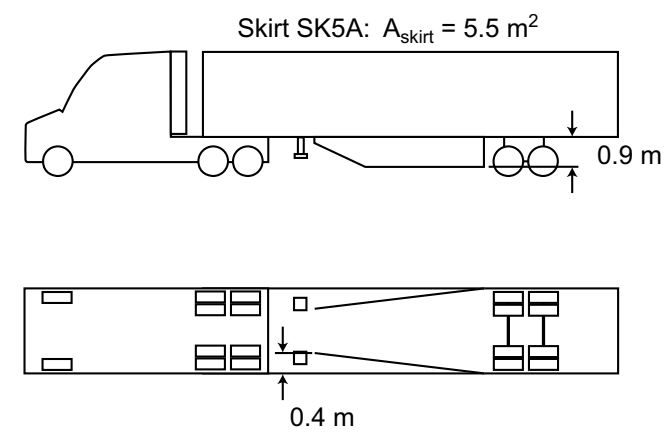

f)
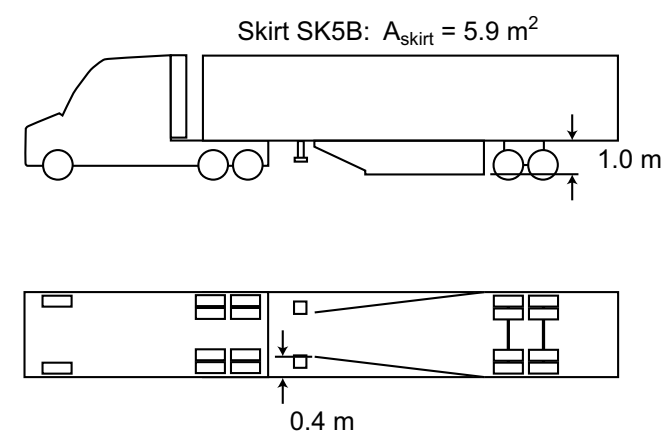

g)
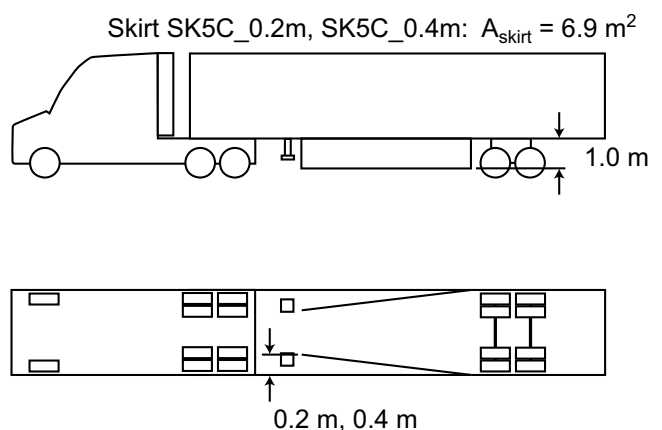

Figure 4: Trailer side skirts (SK). $A_{\text {skirt }}$ denotes the surface area of the trailer skirt. 
a)

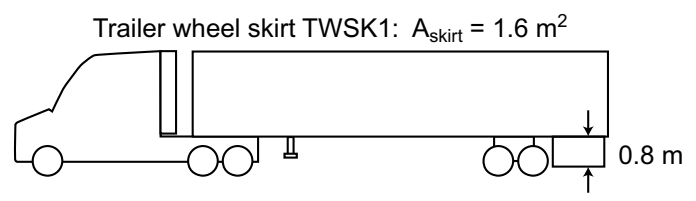

b)

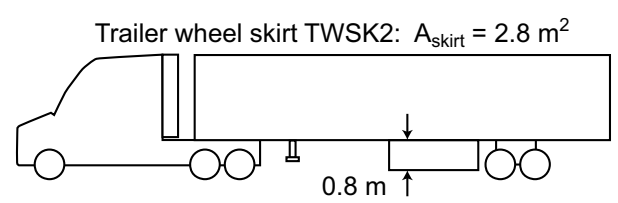

c)
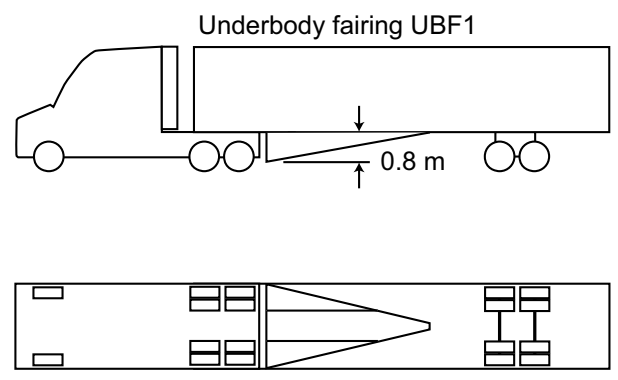

d)
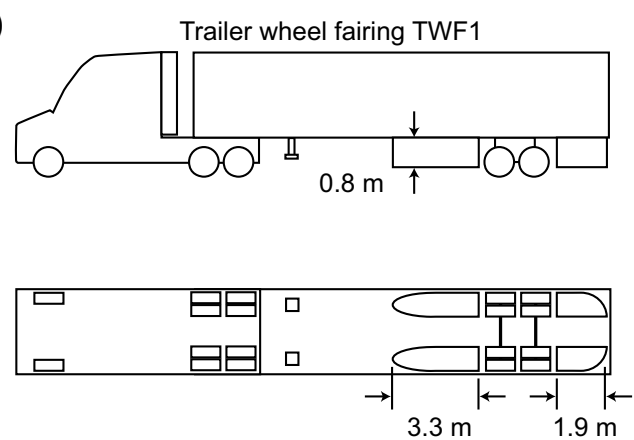

e)

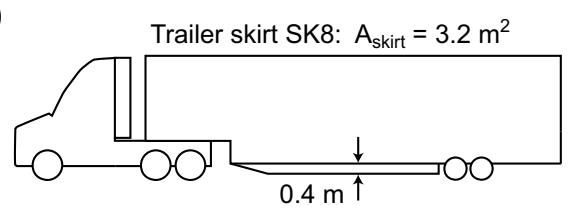

f)

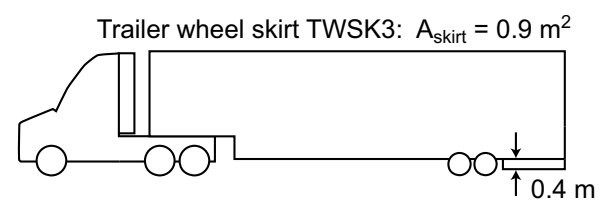

Figure 5: a-b, e-f) Trailer side skirts (SK) and c-d) underbody devices. $A_{\text {skirt }}$ denotes the surface area of the trailer skirt. 
a)

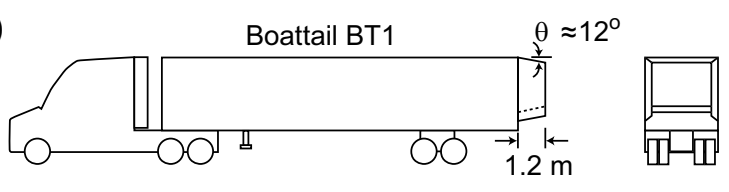

b)

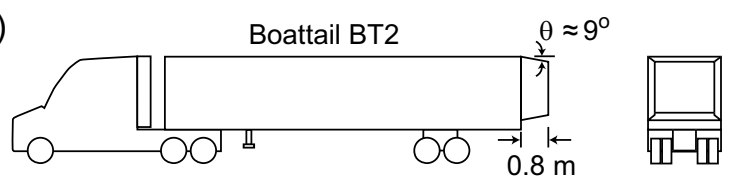

c)

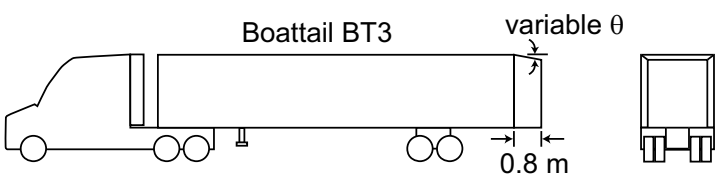

d)

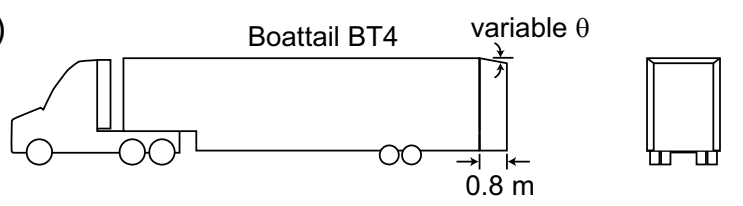

Figure 6: Trailer boattails (BT) for the a-c) straight-frame (SF) trailer and the d) dropframe (DF) trailer. Boattails a-b) are 4-sided and c-d) are 3-sided. 
a)
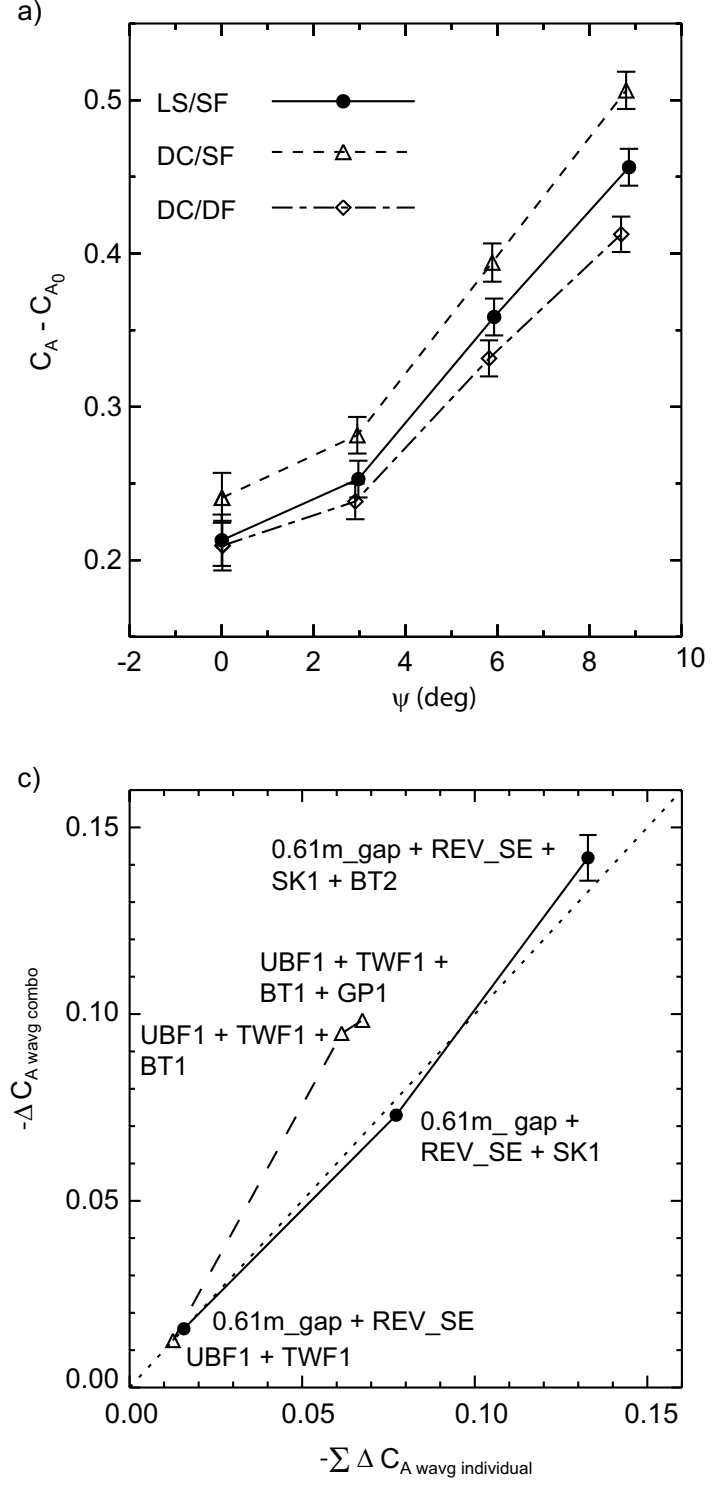

b)

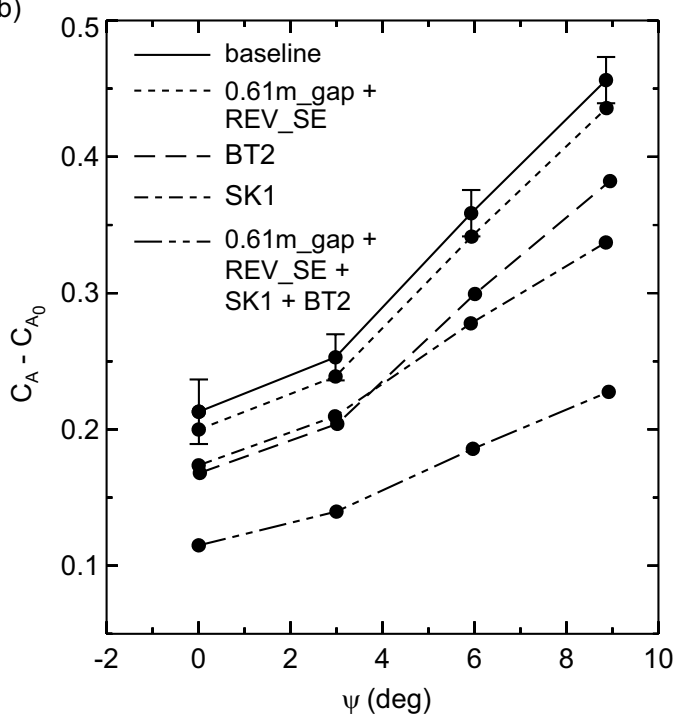

Figure 7: a) Body-axis drag coefficients as a function of the vehicle yaw angle for the three baseline configurations (LS-long-sleeper tractor, DC-day-cab tractor, SF-straightframe trailer, DF-drop-frame trailer) and b) for the LS/SF configuration with drag reduction devices and modifications on the tractor-trailer gap (0.61m_gap + REV_SE-0.61 $\mathrm{m}$ tractor-trailer gap with revised side extenders), underbody (SK1-trailer skirt), and base (BT2-boattail). Note that the body-axis drag coefficients are relative to an arbitrary value, $C_{A_{0}}$. The 0.61m_gap + REV_SE $+\mathrm{SK} 1+\mathrm{BT} 2$ data in b) is the drag curve resulting from the simultaneous installation of the three drag reduction devices and modifications. c) Reduction of the wind-averaged drag coefficient for multiple device installations on the LS/SF configuration. The horizontal axis is the linear summation of the drag reduction values when the devices are installed individually, while the vertical axis is the drag reduction that results when the devices are installed simultaneously with one another. The drag reduction values from multiple devices that combine in a perfectly linear fashion fall upon the $45^{\circ}$ dashed line. 


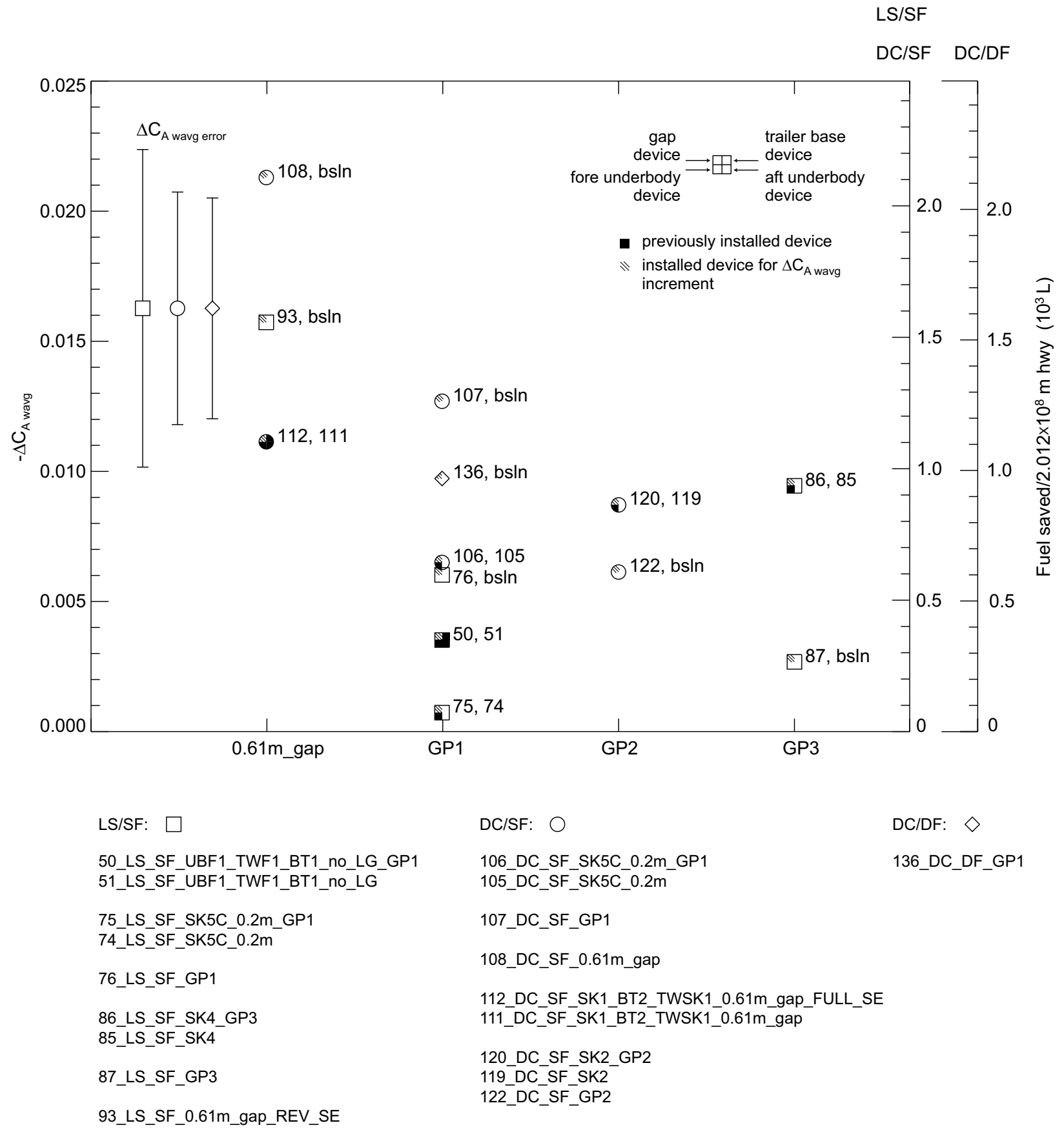

Figure 8: Incremental reduction in the wind-averaged drag coefficient and estimated highway fuel usage for the various tractor-trailer gap devices and modifications. LS-long-sleeper tractor, DC-day-cab tractor, SF-straight-frame trailer, DF-drop-frame trailer, GP-gap device, FULL_SE-full side extenders, REV_SE-revised side extenders, 0.61m_gap-0.61 m tractor-trailer gap, SK-trailer skirt, TWSK-trailer wheel skirt, TWF-trailer wheel fairing, UBF-trailer underbody fairing, BT-boattail, LG-trailer landing gear. See Figures 2-6 for schematics of the vehicle configurations and devices. 


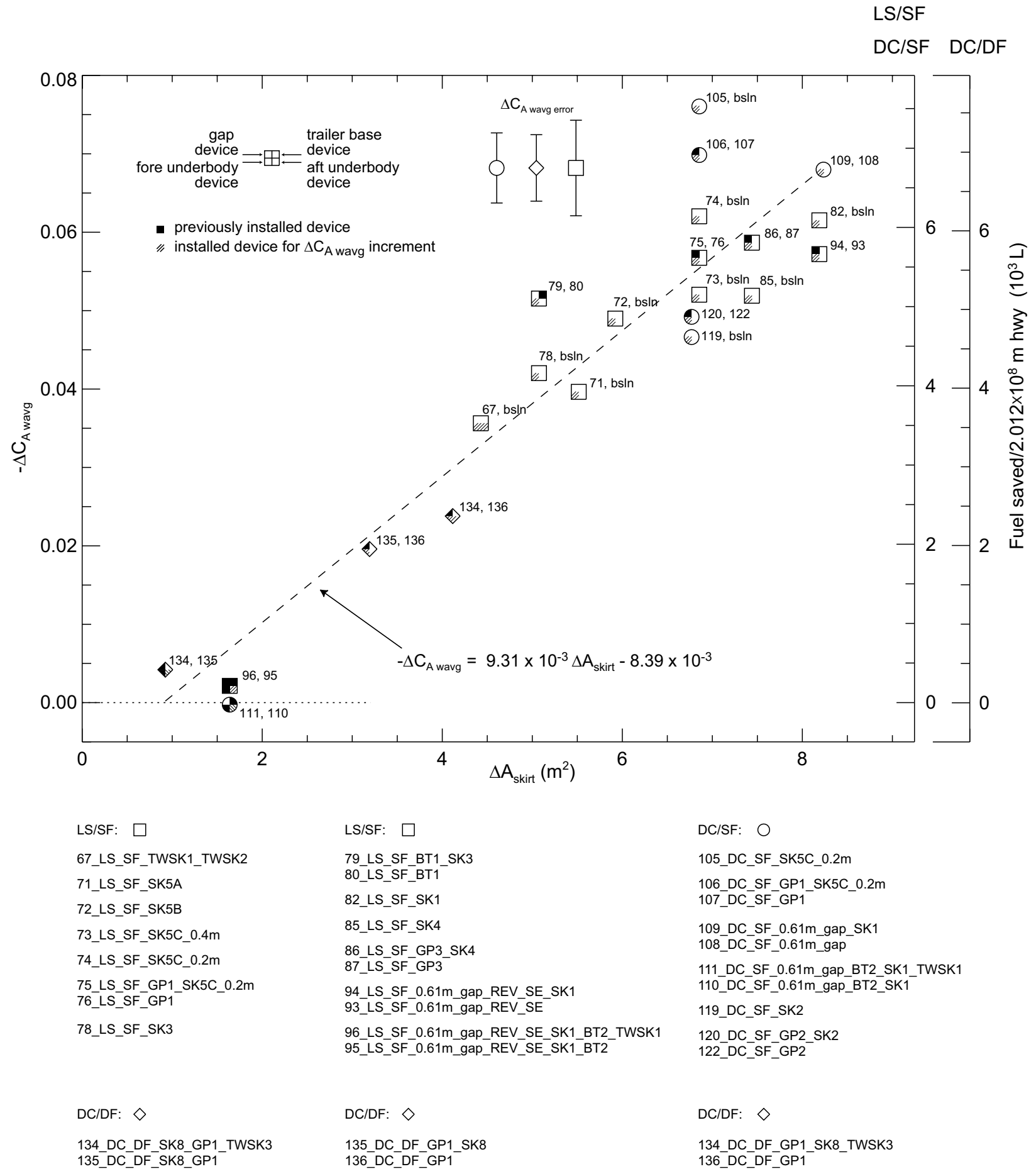

Figure 9: Incremental reduction in the wind-averaged drag coefficient and estimated highway fuel usage as a function of the incremental skirt area for the various trailer skirt (SK) devices. See the caption in Figure 8 for the configuration definitions. 


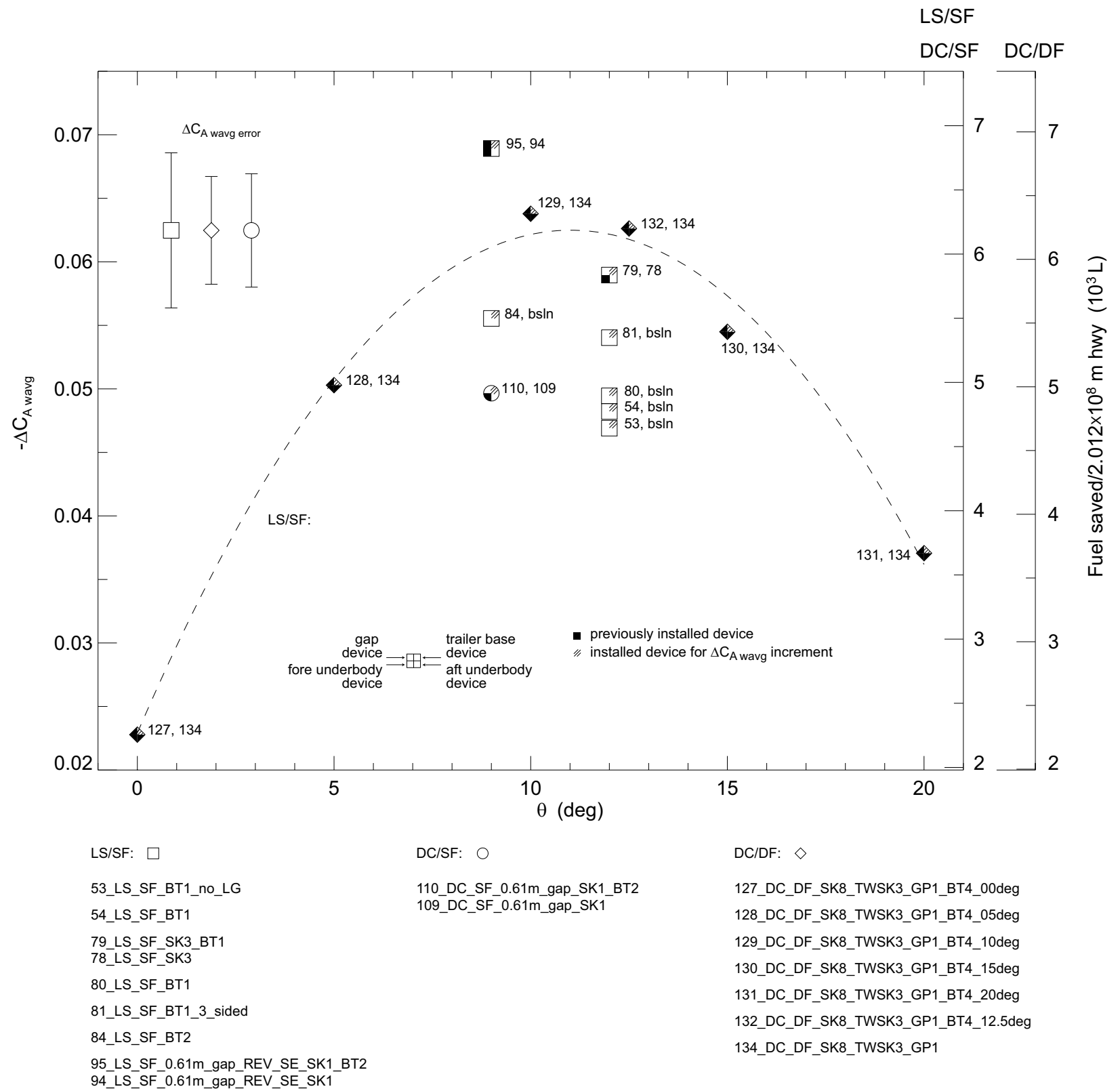

Figure 10: Incremental reduction in the wind-averaged drag coefficient and estimated highway fuel usage as a function of the boattail deflection angle for the various trailer boattail devices (BT). The dashed curve is a second-order polynomial fit to the day-cab/drop-frame trailer (DC/DF) data for boattail 4 (BT4). The maximum $-\Delta C_{A_{\text {wavg }}}$ of this curve fit is at $11 \pm 2^{\circ}$. See the caption in Figure 8 for the configuration definitions. 


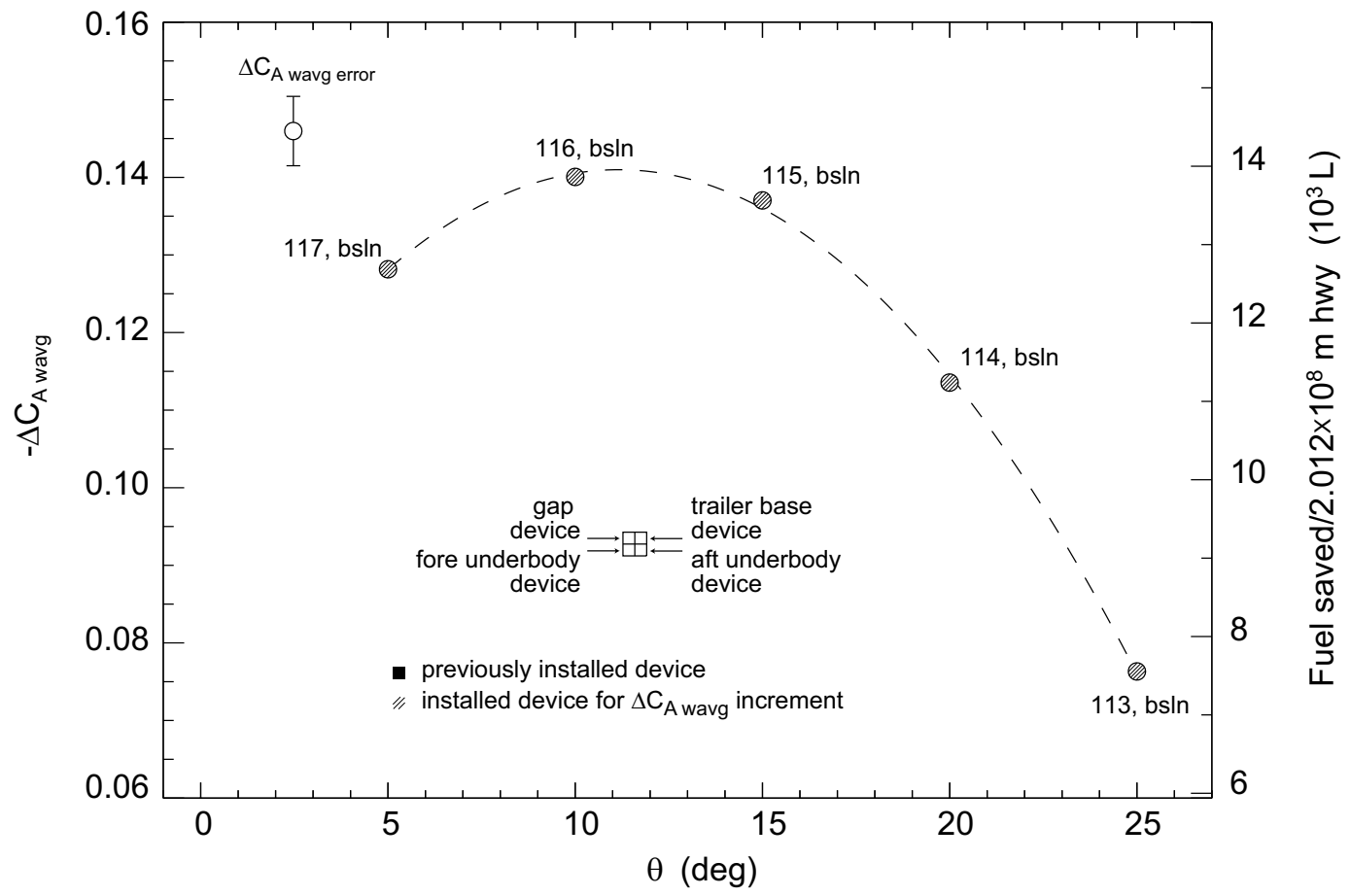

$\begin{array}{ll}\text { 113_DC_SF_0.61m_gap_SK1_TWSK1_BT3_25deg } & \text { 116_DC_SF_0.61m_gap_SK1_TWSK1_BT3_10deg } \\ \text { 114_DC_SF_0.61m_gap_SK1_TWSK1_BT3_20deg } & \text { 117_DC_SF_0.61m_gap_SK1_TWSK1_BT3_05deg } \\ \text { 115_DC_SF_0.61m_gap_SK1_TWSK1_BT3_15deg } & \end{array}$

Figure 11: Reduction in the wind-averaged drag coefficient and estimated highway fuel usage relative to the baseline day-cab/straight-frame trailer (DC/SF) configuration as a function of the boattail 3 (BT3) deflection angle. The maximum $-\Delta C_{A_{\text {wavg }}}$ of the secondorder polynomial curve fit is at $11 \pm 2^{\circ}$. See the caption in Figure 8 for the configuration definitions. 
Fuel saved $/ 2.012 \times 10^{8} \mathrm{~m}$ hwy $\left(10^{3} \mathrm{~L}\right)$

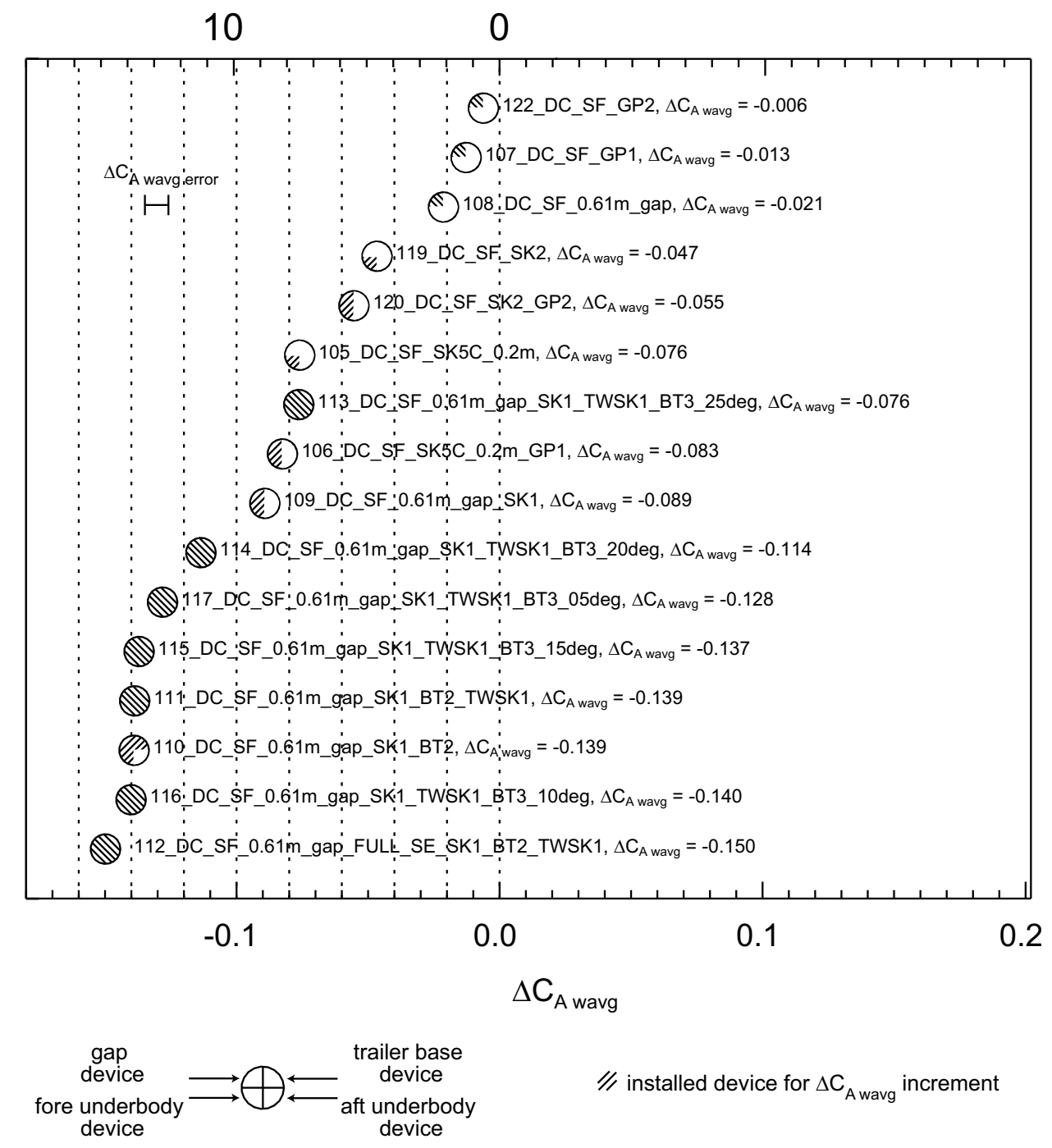

Figure 12: Reduction in the wind-averaged drag coefficient and estimated highway fuel usage for the day-cab/straight-frame trailer (DC/SF) configuration relative to the baseline DC/SF configuration. See the caption in Figure 8 for the configuration definitions. 


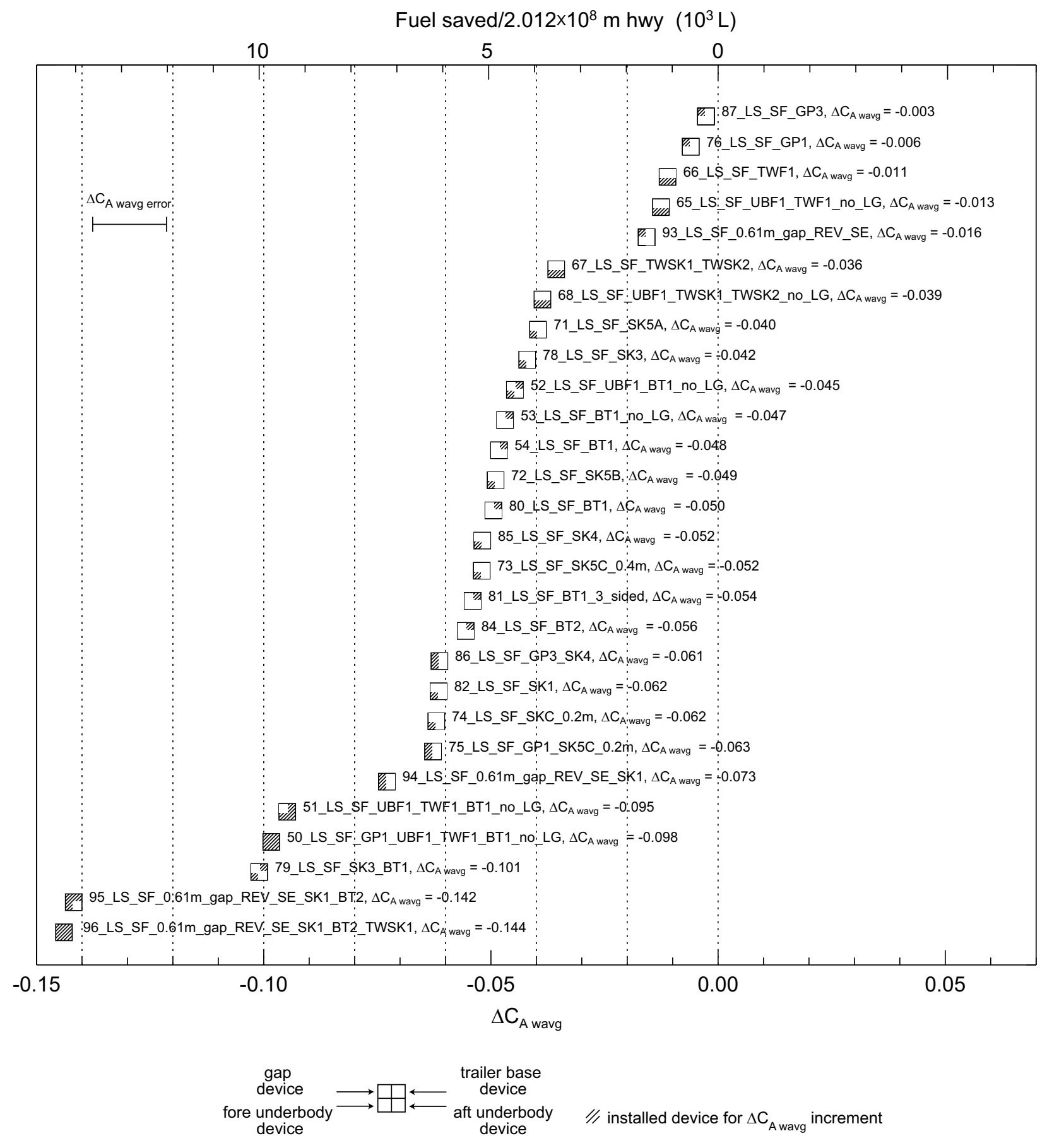

Figure 13: Reduction in the wind-averaged drag coefficient and estimated highway fuel usage for the long-sleeper/straight-frame trailer (LS/SF) configuration relative to the baseline LS/SF configuration. See the caption in Figure 8 for the configuration definitions. 
Fuel saved $/ 2.012 \times 10^{8} \mathrm{~m}$ hwy $\left(10^{3} \mathrm{~L}\right)$

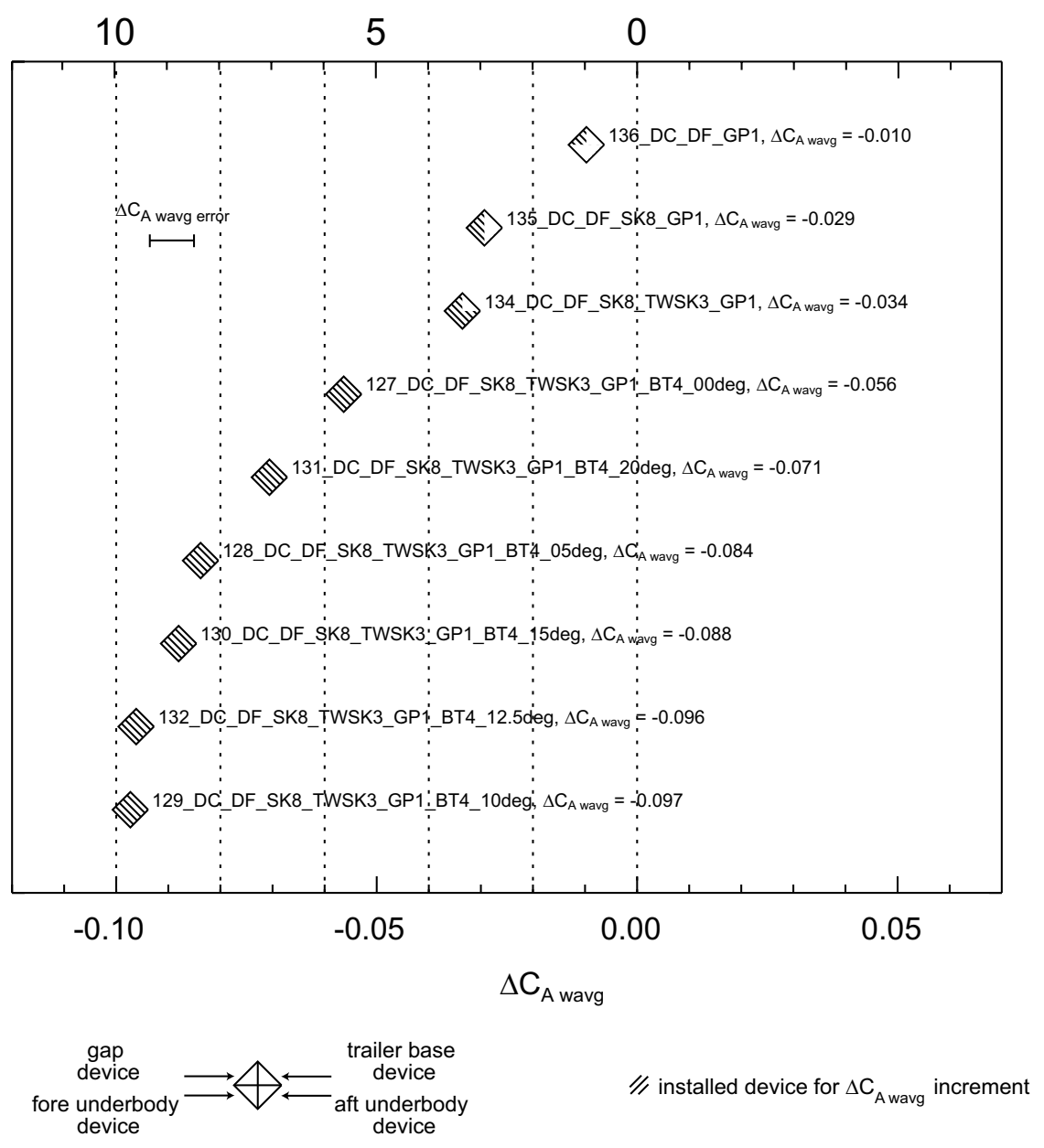

Figure 14: Reduction in the wind-averaged drag coefficient and estimated highway fuel usage for the day-cab/drop-frame trailer (DC/DF) configuration relative to the baseline DC/DF configuration. See the caption in Figure 8 for the configuration definitions. 